Windeler, J.B., Maruping, L M., Robert, L. P., Riemenschneider, C. JAIS (forthcoming)

\title{
http://aisel.aisnet.org/jais/forthcoming.html E-profiles, Conflict, and Shared Understanding in Distributed Teams
}

\begin{abstract}
In this research, we examine the efficacy of a technological intervention in shaping distributed team members' perceptions about their teammates. We argue that by exposing distributed team members to electronic profiles (e-profiles) with information emphasizing their personal similarities with one another, distributed teams should experience lower levels of relational and task conflict. In turn, reductions in conflict should facilitate a shared understanding among team members, which should increase their team effectiveness. The results of a laboratory experiment of 46 distributed teams generally support these assertions. Specifically, we find that a simple, technological intervention can reduce task conflict in distributed teams, which, in turn, improves shared understanding and team effectiveness. We also uncover important differences in the antecedents and impacts of relational and task conflict. Although we find that the e-profile intervention is effective in explaining task conflict $\left(R^{2}=.41\right)$ it was quite poor in predicting relational conflict $\left(R^{2}=.03\right)$. The model explains $33 \%$ and $43 \%$ of the variance in shared understanding and team effectiveness, respectively. Taken together, the results of this research suggest that the information shared about team members in distributed team settings has important implications for their ability to collaborate, achieve a common understanding of their work, and accomplish their task effectively. We suggest that e-profiles may be a useful intervention for management to enhance effectiveness in distributed teams.
\end{abstract}

Keywords: distributed teams, team conflict, shared understanding, collaboration 
Despite numerous opportunities for managing and leveraging collaboration using distributed teams, conflict continues to be a major challenge (O'Leary and Mortensen, 2010; Ortiz de Guinea et al., 2012; Polzer et al., 2006). Conflict is defined as the perceived incompatibilities and disagreements between individuals (Boulding, 1962; Jehn, 1997). Managing conflict can be challenging when teams are distributed - i.e., not co-located, never meet face-to-face, and communicate exclusively through information and communication technologies (ICT) (Beise et al., 2004; Dennis et al., 2012; Griffith et al., 2003b). In particular, the impersonal nature of technology-mediated communication and the lack of a shared context can make teams vulnerable to conflict (Kankanhalli et al., 2007; Staples and Zhao, 2006). In addition, distributed teams are often temporarily assembled for the sole purpose of accomplishing a specific set of tasks and then disbanded (Cohen and Bailey, 1997; Sundstrom et al., 1990). Temporary teams (e.g., task forces, action teams), distributed or not, often lack the time needed to develop effective ways to manage team conflict (Mortensen and Hinds, 2001). Taken together, distributed teams are just as likely to have conflict as co-located teams and may lack the ability to deal with it effectively (Cramton, 2001; Mortensen and Hinds, 2001).

Another problem associated with conflict in distributed teams is derived from the interpersonal differences in values and beliefs among team members (Cramton, 2001; de Rooija et al., 2007; Hinds and Mortensen, 2005). Such differences, in and of themselves, are not problematic and, in fact, can be desirable because they provide teams with a wealth of ideas and perspectives (Dahlin et al., 2005; Giambatista and Bhappu, 2010). However, as we will explain in greater detail, such differences can have the unfortunate effect of making team members less receptive to the ideas and perspectives of others whom they perceive to be different from themselves (Harrison et al., 2002). 
Interpersonal differences, paired with a lack of shared history and context, can make it difficult for distributed teams to achieve a shared understanding about how to approach a problem (Cramton, 2001; de Rooija et al., 2007; Hinds and Mortensen, 2005). Shared understanding is the extent to which team members have similar or overlapping beliefs about their tasks, objectives, and problem-solving approaches (Cannon-Bowers et al., 1993; Ko et al., 2005; Robert et al., 2008). Shared understanding is particularly important for distributed teams because it enables team members to communicate effectively across dispersed settings by anticipating one another's needs (Cramton, 2001; Robert et al., 2008). This explains, in part, why shared understanding has been linked to higher effectiveness in distributed teams (Cramton, 2002; Hinds and Mortensen, 2005; Robert et al., 2008).

Although conflict in distributed teams is an important topic, the literature is lacking in terms of details of team conflict's emergence and impacts in a group setting (Ortiz de Guinea et al., 2012). The current literature examining conflict in distributed teams has focused on understanding how conflict or conflict management style directly impact team effectiveness (Kankanhalli et al., 2007; Montoya-Weiss et al., 2001; Paul et al., 2004; Staples and Zhao, 2006). However, much less is known about how to prevent conflict or the mediating mechanisms by which conflict impacts the effectiveness of distributed teams. Yet, both are vital to understanding how to mitigate the negative effects of team conflict.

Although reported approaches for conflict prevention are scarce, there are some. One approach suggested by several scholars is to have a face-to-face meeting among distributed team members early in the team's lifecycle (Jarvenpaa et al., 1998; Kirkman et al., 2002; MontoyaWeiss et al., 2001). Although this may be effective, it is not always possible due to geographic distances or it can be impractical because of the time and cost associated with such arrangements. This suggests that alternate approaches to preventing team conflict are needed. 
Carte and Chidambaram (2004) offer another approach to managing conflict. They suggest that communication technologies can play an important role in helping distributed teams overcome problems like conflict that are often associated with team diversity. Carte and Chidambaram (2004) suggest that communication technologies could be used early in the life of a team to mask the surface-level differences among team members. Surface-level diversity, also referred to as demographic or high-visibility differences, are based on attributes that are overt and immediately apparent upon meeting someone, such as age, gender or race (Bell, 2007; Harrison et al., 2002). Although communication technologies that offer no visual or vocal cues are likely to mask surface-level diversity, they are unlikely to suppress deep-level diversity. Deep-level differences are those based on underlying cognitive attributes, such as values, attitudes, knowledge, experiences and personality (Bell, 2007; Harrison et al., 2002). Research has found that when distributed team members are not provided with visual or vocal cues about their teammates' surface-level diversity they tend to rely on deep-level differences when forming perceptions about other team members (Griffith et al., 1998). Deep-level differences are posited to have the same negative effects as surface-level diversity in distributed teams (Hinds and Bailey, 2003; Kankanhalli et al., 2007).

When properly channeled, deep-level diversity has been empirically shown to result in positive outcomes because it exposes teams to a wealth of ideas and perspectives less present in homogeneous teams (Giambatista and Bhappu, 2010; Robert et al., 2008). In fact, distributed teams are often assembled for the sole purpose of bringing together individuals with diverse knowledge and experiences to address complex problems; as such, they often have more deeplevel diversity than their co-located counterparts (Hinds and Bailey, 2003; Hinds and Mortensen, 2005). Despite the importance of deep-level diversity to distributed teams, our current approaches offer very little insight into how to address the problems associated with it. This begs the question: How can distributed teams prevent conflict induced by deep-level 
differences, which can often impede the development of a shared understanding needed to facilitate better team effectiveness?

Our objective is to advance the literature by developing insight about how technology can be leveraged to reduce conflict, enhance shared understanding and ultimately increase the effectiveness of distributed teams. Because technology plays a central role in the facilitation of communication in distributed teams with dispersed team members, we advocate a technologydriven approach. Specifically, our approach leverages the very mechanism that is often identified as being the source of the negative effects of team diversity: the social categorization process (Brewer, 1979).

According to social categorization theory (SCT), people have a tendency to group others into social categories and regard similar others as part of the "in-group" and dissimilar others as part of the "out-group" (Turner, 1985). Individuals prefer to interact with others like them and avoid interacting with others not like them (Brewer, 1979; Turner, 1985). The belief that others are different (i.e., out-group members) has been found to reduce cohesion, trust and perceptions of performance in distributed teams (Garrison et al., 2010). Recent work on diversity in distributed teams suggests that technology can be leveraged to mask surface-level differences among team members and help teams overcome the problems associated with the social categorization process (Giambatista and Bhappu, 2010). This research provides support for Carte and Chidambaram's (2004) assertion that communication technologies can act as an early intervention by masking surface-level differences in order to avoid the problems associated with the social categorization process.

In this study we attempt to expose distributed teams to their shared deep-level diversity attributes early in the team's development in hopes of inducing the social categorization process in such a way that distributed team members perceive similarities with each other (i.e., in-group 
members), irrespective of their actual deep-level differences. In doing so, we identify a way to channel deep-level, attribute-induced social categorization behavior by using an IT artifact (eprofiles) to emphasize what team members have in common rather than masking deep-level attributes. By using an IT artifact to shape the deep-level attributes that are revealed, we can affect team members' perceptions about the degree of deep-level diversity in a distributed team while leaving the actual deep-level diversity intact. The benefit of this approach is that it mitigates the negative out-group dynamics brought about by deep-level differences and retains the diverse ideas reflected in these deep-level attributes. This allows us to address a potential tradeoff between reducing counterproductive group conflict and groupthink tendencies that suppress productive debate.

Our e-profile is a technical intervention that can retain the underlying differences but help reduce conflict, thus making team members more receptive to viewpoints that differ from their own. Similar to Carte and Chidambaram (2004), our approach offers an early intervention, but unlike Carte and Chidambaram (2004), who focus on masking surface-level differences, we focus on channeling perceptions of similarity to reduce conflict in distributed teams. Rather than avoiding the naturally occurring social categorization process, our approach relies on it. This early intervention should reduce conflict and make it easier to resolve. We elaborate on this in the next section.

In addition to providing an intervention to minimize conflict in distributed teams, our study offers several contributions to the literature. We contribute to the literature by examining the role of technology as an upstream antecedent of team conflict and theorizing the downstream consequences of different types of conflict. To our knowledge, no prior studies have examined these effects at this level of granularity. Understanding these nuanced effects is important because research has demonstrated that different forms of conflict can have very different 
effects on team functioning, including both positive and negative outcomes (De Dreu and Weingart, 2003). We shed light on these effects and in doing so we advance a deeper understanding of the role that technology can play in attenuating conflict and enhancing shared understanding in distributed teams.

\section{Background and Theory Development}

In this section, we provide an overview of the relevant literature on conflict in teams, specifically focusing on its impact on team effectiveness and its emergence in distributed team settings. We then discuss social categorization as the overarching lens that brings together team member differences in values and experiences, and the emergence of conflict in team settings.

\section{Conflict in Teams}

A significant corpus of work has examined conflict in co-located teams (Jehn, 1997; Jehn and Chatman, 2000; Jehn et al., 1999; Rogers and Bhowmik, 1970). Although the literature has identified multiple types of conflict that arise in teams, two types receive the majority of attention from researchers: relational conflict and task conflict (e.g., Amason and Sapienza, 1997; Barki and Hartwick, 2004; De Dreu and Weingart, 2003; de Wit et al., 2012; Jehn, 1995; Kankanhalli et al., 2007; Montoya-Weiss et al., 2001; Mooney et al., 2007; Rispens, 2012). Relational conflict (also called affective or interpersonal conflict) represents personal disagreements between people and is characterized by anger and dislike (Priem and Price, 1991). Task conflict (also referred to as cognitive conflict) refers to disagreements about the content of the task being performed (Jehn, 1995). Taken together, relational and task conflict represent two distinct types of conflict. Some of the literature we reference includes examination of process conflict i.e., conflict about the way the task is performed. We chose not to include this type of conflict. Process conflict provides a more nuanced view of conflict related to the task. In fact, some suggest that process conflict is a sub-dimension of task conflict (Barki and Hartwick, 2004). Our 
focus on relational conflict and task conflict follows that of many others (e.g., Amason and Sapienza, 1997; De Dreu and Weingart, 2003; de Wit et al., 2012; Kankanhalli et al., 2007; Mooney et al., 2007; Rispens, 2012) and we felt this framing was justified given that the contribution of this paper does not involve a nuanced account of task-related conflict.

Despite the long tradition of conflict research in co-located teams there is still much debate about the impact of conflict on team outcomes. Most scholars seem to agree that relationship conflict generally has a negative influence on team outcomes (see De Dreu and Weingart, 2003; de Wit et al., 2012, for reviews). But research has found that task conflict can have potential benefits. This line of research suggests that a moderate levels of task conflict can be healthy when it stimulates debate and consideration of alternative solutions (Jehn and Chatman, 2000; Priem and Price, 1991). In this sense, task conflict helps reduce confirmation biases in decisionmaking and enhances innovation. However, such benefits are contingent on a team's ability to resolve differences among its members, which may be difficult for some teams, particularly those that are distributed or work together for only a short period of time. In these cases task conflict can be expected to decrease team effectiveness.

Two meta-analyses examined the complex relationship between task conflict and team effectiveness. De Dreu and Weingart (2003) examined 24 studies on relationship conflict and team effectiveness, finding a consistently negative relationship. They also examined 25 studies on task conflict and team effectiveness. Although five of those studies found positive correlations between team effectiveness and task conflict, the overall average correlation across all studies was negative and significant. The degree of this negative relationship depended on task type and the amount of correlation between relationship and task conflict. A recent followup meta-analysis examined 80 new studies (de Wit et al., 2012). Like De Dreu and Weingart (2003), this recent study found relational conflict to be negatively related to team outcomes. 
However, unlike the findings of De Dreu and Weingart (2003), task conflict did not have an overall negative association with team outcomes; rather, in many cases task conflict was positively related to team effectiveness. The strength of this positive association between task conflict and team effectiveness varied by the type of team, task and outcome as well as the lack of correlation between relationship and task conflict (de Wit et al., 2012). Taken together it would appear that the association between task conflict and team effectiveness is complex and may be influenced by a variety of factors.

\section{Social Categorization}

Conflict is an important topic in the study of distributed teams (Kankanhalli et al., 2007; Mannix et al., 2002; Miranda and Bostrom, 1993; Paul et al., 2004). Distributed teams can often constitute an environment that is prone to inciting conflict (Hinds and Bailey, 2003; Mannix and Neale, 2005). Communication technologies tend to bring together individuals with diverse backgrounds (Boh et al., 2007) who are physically dispersed across locations (Robert et al., 2008). Consequently, there is often a lack of shared context among team members, which can precipitate conflict (Cramton, 2002). In fact, a number of studies have found that team dispersion increases the likelihood of conflict (Cramton, 2001; Hinds and Mortensen, 2005; Kankanhalli et al., 2007).

Differences in backgrounds, values and experiences among team members have been a source of conflict in co-located teams (Goyal et al., 2008; Jehn, 1995) and distributed teams (Paul et al., 2004). This is because people with different backgrounds, values and experiences naturally have different ways of viewing the same problem (Cronin and Weingart, 2007) and different opinions on the approaches to solve it, potentially leading to disagreements (Pelled, 1996; Pelled et al., 1999). The differences become detrimental when individuals believe they are 
different from their teammates (Harrison et al., 2002). These perceptions of differences are propelled by the social categorization process.

The social categorization process is driven by an individual's need for social comparison and is accomplished when people categorize those around them into social groups (Tajfel and Turner, 1979; Tajfel and Turner, 1986; Turner, 1985). These categories are defined by the prototypical characteristics abstracted from group members that are ultimately used as a basis for comparison. Through this social comparison process, people come to regard themselves as members of one group, referred to as the in-group, in comparison with other groups, which become the out-group. The purpose of creating these social in-groups and out-groups is twofold. First, it allows individuals to cognitively partition their social environment, giving structure and definition to an otherwise chaotic social environment. Second, categorization allows an individual to locate and define him or herself within the environment. Studies have shown that people tend to favor those they see as belonging to their in-group and discriminate against those in the out-group (e.g., Brewer, 1979). Social categorization theory has made significant contributions to the explanation of in-group bias, stereotyping, and responses or reactions to intra- and intergroup homogeneity.

Taken together, social categorization suggests that personal attributes such as values and experiences inform one's psychological formation of in-groups and out-groups and can subsequently shape their collaboration with others in team settings. On this basis, we propose using e-profiles (a technological intervention) to expose team members to their deep-level similarities. This, in turn, should invoke the social categorization process in such a way that these team members see their teammates as in-group members. When this occurs these individuals should have higher levels of perceived similarity. Perceived similarity should decrease conflict which, in turn, should facilitate shared understanding and, ultimately, team 
effectiveness. The use of e-profiles accomplishes this in two ways: one, it draws attention to team members' similarities, shaping their perceptions; and two, it anchors their perceptions of similarity in deep-level attributes that are relevant to an individual's identity (e.g., values, beliefs) and the work the team performs. The e-profiles offer a mechanism by which we can further our understanding of human behavior in a distributed team setting. Our research model is shown in Figure 1 and in the next section we develop the logic behind the hypothesized relationships in the model.

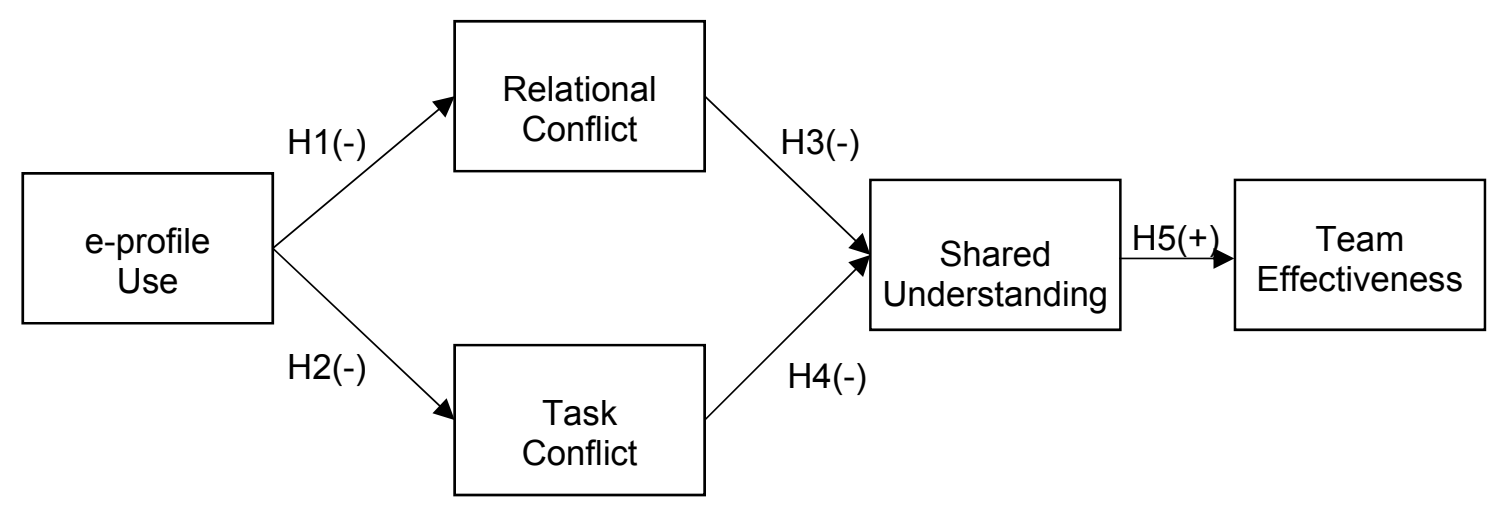

Figure 1. Theoretical Model

\section{Hypotheses Development}

Research suggests that "if differences are to be meaningful, they must be perceived" (Harrison et al., 2002, p. 1032). Consistent with this contention, empirical research has found that compared to actual diversity, perceived diversity explains more variance in team effectiveness (Harrison et al., 2002). Our model is grounded upon the notion that exposure to information about team-member similarity lessens team conflict because relationships are generally more harmonious between individuals who perceive themselves to be similar. Distributed team members can be exposed to information about their similarities with other team members through e-profiles. Thus, e-profiles represent a means to manage conflict and perceptions of 
similarity, and the accompanying behaviors such as in-group categorization are the theoretical mechanisms by which this occurs.

The use of the e-profiles represents an early intervention. In the early stages of team development, distributed team members have very little, if any, information about one another, causing a significant amount of uncertainty about their collaborators (Robert et al., 2009). In the absence of visual or vocal cues depicting who their teammates are, team members are likely to glean whatever information they can about their teammates through the content of team communications. Teammates who are exposed early to information about their similarities in values, beliefs and experiences (i.e., deep-level attributes) through e-profiles should perceive the team to be more homogeneous, giving rise to in-group categorization. This is because when team members perceive themselves to be part of a similar in-group, they minimize the significance of differences that later emerge (Brewer, 1993; Zellmer-Bruhn et al., 2008). This is consistent with other research on intragroup relations that found that perceptions of similarity among team members promote social integration (Harrison et al., 2002). Social integration is composed of several sub-dimensions: trust, cohesion and satisfaction (Rico et al., 2007). Trust, cohesion and satisfaction have all been found to decrease team conflict (e.g., Jehn, 1997; Pelled, 1996). Thus, it stands to reason that information about team member similarity should help facilitate perceived similarities and reduce team conflict. Below we present specific arguments about the impact of e-profiles on both relationship and task conflict.

We expect conflict related to interpersonal disagreements and dislike - relational conflict — to occur less in teams exposed to information about their similarities. As a result of social categorization, people tend to favor those they believe are in their in-group while sometimes discriminating against those in the out-group (e.g., Brewer, 1979). This favoritism can help reduce relational conflict in two ways. One, individuals are drawn to others they perceive to be 
similar, which creates stronger interpersonal bonds. These strong interpersonal bonds reduce relational conflict because individuals tend to want to maintain good interpersonal relationships with others who are similar to themselves because it reinforces and confirms the validity of their own attitudes, opinions and choices (Byrne, 1971). Two, individuals strive to maintain a positive perception of the group they feel they belong to, in order to increase self-esteem and reduce cognitive dissonance (Tajfel and Turner, 1986). As a result, even when problems that could lead to relational conflict arise, individuals who believe they are similar to their teammates are more likely to blame those problems on the situation and not their teammates (Pettigrew, 1979). This is particularly important for members of distributed teams in which dispersion and technologymediated communications can often lead to blame being placed on teammates rather than the situation (Alnuaimi et al., 2010; Cramton, 2001). Taken together, we would expect the use of eprofiles to decrease the occurrence of relational conflict in distributed teams.

H1: Exposure to information on the deep-level similarities of team members through eprofile use will negatively influence relational conflict in distributed teams.

Task conflict should occur less in teams exposed to information about their similarities for several reasons. Task conflict represents disagreements about the content and goals of the task itself (Jehn, 1997). Such disagreements often represent a struggle for control (Jehn, 1997). However, perceived similarity induces cooperation and an orientation toward enhancing mutual power, rather than individual power (Deutsch et al., 2006). When individuals believe they are similar to their team members, they are more likely to behave in ways that benefit the group as a whole, rather than any one individual (Hinds and Mortensen, 2005). This means that when perceptions of similarity are high, individuals are more likely to put their personal preferences aside and work together for a common purpose (Deutsch et al., 2006). This cooperative stance 
produces a climate where roles and responsibilities are amicably shared or divided and where task-related decisions are jointly made rather than disputed (Hinds and Mortensen, 2005).

Perceptions of similarity have also been found to engender greater perspective-taking among individuals (Cialdini et al., 1997). Perspective-taking is the process by which individuals put themselves in another person's shoes, so to speak, and try to understand the rationale behind the other person's view (Cialdini et al., 1997). When perspective-taking occurs, team members are more likely to appreciate each teammate's point of view (Cialdini et al., 1997). This, in turn, increases the likelihood that they will consider and fairly evaluate each teammate's input regarding the task, which should decrease the occurrence or escalation of task conflict.

We further suggest that task conflict is less likely to occur in teams exposed to information about their similarities because differences regarding the task will either be de-emphasized or accommodated. Team members who believe they are similar to one another are likely to deemphasize their differences because individuals often ignore differences with others when they believe they are similar to them in other ways (Deutsch et al., 2006). This is, in part, because individuals often over-estimate the extent of their similarities with others. Research has shown that when individuals believe they are similar in one area with others they assume that they are similar in other areas (McPherson et al., 2001). Moreover, team members are more likely to value the views of others like them when differences regarding the task become salient (Hogg and Hains, 1998). Individuals tend to think favorably about themselves and their own views. This favorable impression is often extended to other in-group members. Therefore, the more team members believe they are similar the more they should value their teammates' views about the task. When individuals value the views of others, they are more likely to accommodate or integrate those views into team decisions. Such efforts should also reduce task conflict. 
H2: Exposure to information on the deep-level similarities of team members through eprofile use will negatively influence task conflict in distributed teams.

Relational and task conflict are theorized to have downstream consequences for shared understanding. The benefits of shared understanding are attributed to enhanced coordination, knowledge exchange and interpersonal integration. Relational conflict is expected to detract from the development of shared understanding, because it disrupts coordination and knowledge exchange. The suspicion and resentment that occur as a result of relational conflict (Jehn, 1997) can cause team members to withhold information that is critical for the development of shared understanding. Relational conflict disrupts interpersonal integration by directing members' attention toward reducing threats, increasing power and attempting to build cohesion (Jehn, 1997). When relational conflict is high, research shows that team members spend a great deal of time on interpersonal aspects of group functioning rather than task-relevant activities (Evan, 1965) that can lead to shared understanding.

H3: Relational conflict will negatively influence shared understanding in distributed teams.

Task conflict is also expected to negatively influence shared understanding. As with relational conflict, task conflict represents additional noise that may detract from the team's focus on understanding the team and task. Disagreements about task goals or decisions are likely to interfere with the coordination, knowledge exchange and processing necessary to achieve shared understanding. However, research suggests that task conflict actually has positive implications for decision-making effectiveness by incorporating devil's advocacy roles and generating debate about alternative solutions (Jehn and Chatman, 2000). Nevertheless, these gains in decision-making effectiveness are contingent upon a team's ability to effectively negotiate compromises. In other words, task conflict may be beneficial for team effectiveness, 
but only to the extent to which it can be effectively resolved. Research suggests that the nature of the task and team are important factors contributing to whether some level of task conflict is productive (Arazy et al., 2011; Kankanhalli et al., 2007). We maintain that shared understanding among distributed team members will not benefit from task conflict because distributed teams are less equipped to resolve task conflict (Maruping and Agarwal, 2004). Moreover, short-term teams are at an even greater disadvantage when it comes to making task conflict work for them. The distributed context introduces uncertainty that makes it more difficult to resolve conflict and achieve shared understanding, particularly given the time pressure that short-term teams face.

H4: Task conflict will negatively influence shared understanding in distributed teams.

\section{Shared Understanding}

The importance of shared understanding to team effectiveness has long been recognized (Cannon-Bowers et al., 1993). In many cases, shared understanding has been used as an indication of team readiness to perform assigned tasks (Cannon-Bowers et al., 1993; Mathieu et al., 2000). Recently, the idea of shared understanding has received increased attention among practitioners and academics (Hsu et al., 2011; Pearsall et al., 2010; Robert et al., 2008). This is due, in part, to the increased use of teams that have a diverse membership and rely primarily on technology-mediated communication. Both characteristics have been found to inhibit the development of shared understanding (Hinds and Bailey, 2003). Therefore, understanding how to facilitate shared understanding in distributed teams made up of members with diverse viewpoints presents a new challenge to scholars.

An important consideration related to a shared understanding is the potential for groupthink. Groupthink is defined as the "psychological drive for consensus at any cost that suppresses dissent and appraisal of alternatives in cohesive decision making groups" (Janis, 1972, p. 8). Groupthink is thought to occur when teams are highly cohesive and members grow 
apprehensive of sharing dissenting ideas for fear of disrupting this cohesion (Janis, 1972; 1982). Although we believe the reduction of conflict and enhancement of shared understanding are important facilitators of effectiveness in distributed teams, we recognize the possibility that these conditions could be counter-productive by suppressing the exchange of opposing views, resulting in groupthink. Although groupthink and shared understanding have the potential to be related, shared understanding does not necessarily imply the presence of groupthink. As noted earlier, shared understanding reflects a common understanding of how to approach the problem at hand. Such understanding does not preclude consideration of alternatives or the possibility of entertaining dissenting viewpoints, both of which are characteristics of groupthink.

In this paper, we posit that shared understanding should be positively related to the effectiveness of distributed teams. Several well-established theoretical mechanisms account for this effect. Shared understanding helps to facilitate greater ease with communication and collaboration because team members have a common frame of reference with respect to team member roles and responsibilities and the team's work (Dickey et al., 2006; Hinds and Weisband, 2003; Robert et al., 2008). This common ground can have several important benefits. One, it allows individuals to anticipate the actions of their teammates, reducing the need for monitoring and redundancy in efforts (Hinds and Weisband, 2003). Two, it enhances the ability of teams to integrate knowledge because it facilitates meaningful communication whereby members know what information to exchange and when to exchange it (Robert et al., 2008). This enables teams to rapidly process information into meaningful structures, increasing the efficiency and effectiveness of information exchange (Marks et al., 2000).

Such efficiency gains resulting from shared understanding should facilitate effectiveness by allowing the team to use its resources more effectively. For example, when team members share an understanding of the problem-solving approach they will use for a task, they need not 
expend precious time discussing which approach they should use and who will be involved in executing various aspects of that approach (Robert et al., 2008). Moreover, these efficiency gains improve satisfaction and motivation toward the task because the team has a greater sense of goal direction and team efficacy (Locke and Latham, 1990). Higher satisfaction and motivation ensure that the team keeps its efforts directed at the task and persists in the face of obstacles (Ford, 1992).

H5: Shared understanding will positively influence the effectiveness of distributed teams.

\section{Methodology}

\section{Participants}

We conducted a laboratory experiment to test the hypothesized relationships. One hundred seventy-three undergraduate business students from a medium-size university in the southern United States participated for course credit. Although the use of student subjects is not without its limitations (Colquitt, 2008), we thought it was justified given the nature of our study. Following suggestions of Compeau et al. (2012), we included an assessment of parallelism of subjects, task relevance and subject familiarity with e-profiles (the manipulation) of this study. We were interested in exploring how perceptions of deep-level similarity influence conflict and shared understanding. Given their academic and social experiences working in teams, particularly as business students, we thought the student subjects would be capable of processing the information provided to them through the e-profiles, developing perceptions about team members and acting on those perceptions. Moreover, given college students' extensive use of social networking websites, the format for sharing information among teammates using eprofiles would be familiar and the task they worked on (i.e., a case involving a graduate teaching assistant who accepted a bribe) was relevant to their experiences. Nonetheless, there are limitations to the use of student subjects and we explore this in greater detail in the discussion 
section. Of the 169 participants $^{1}, 31 \%$ (52) were women. The average age was 22.3 years (SD $=4.0)$. Seventy-nine percent of the participants were white, $12 \%$ Asian, $4 \%$ black, $3 \%$ Native American and 2\% Hispanic. Four participants dropped out, so there were 169 participants organized into 46 teams, and the teams were divided equally into two experimental conditions (i.e., 23 with and 23 without exposure to e-profiles). Team size ranged from three to five members, with an average size of 3.67 members.

\section{Task}

Based on our interest in influencing perceptions of deep-level similarity, the primary criterion for selecting the team task was that the task should activate or engage deep-level attributes, such as personal values and attitudes. A secondary criterion for task selection was a relatively objective team effectiveness metric to reduce the possibility of source bias. We selected Straus and McGrath's (1994) judgment task, in which teams were asked to determine disciplinary action for a fictitious case involving a graduate teaching assistant who accepted a bribe from the basketball team's star player to change an exam grade. The case presented five issues requiring solutions. Three of the issues specified punitive action for the student and two issues specified punitive action for the instructor. Three constituencies with competing interests were specified in the case: the athletic department, college faculty, and college administration. Teams were given between three and five alternative solutions to each issue and were asked to discuss the alternatives and agree on one solution for each issue. They were told to attempt to satisfy the conflicting interests among the constituencies and that the more their solution balanced the interests of all parties, the better their team would perform. Team effectiveness was then assessed according to how well teams followed the directive of balancing the interests

\footnotetext{
${ }^{1}$ The original data set was composed of 173 participants; however four of the participants (organized into one team) were unable to complete the experiment, resulting in 169 total participants.
} 
of all parties and the extent to which they were able to reach consensus. This assessment was considered appropriate because a judgment task requires participants to mediate a problem, and consideration and balance of conflicting interests are the primary objectives. Judgment tasks are different from other types of tasks (e.g., intellective, idea-generation) in that they do not have a correct answer; they require teams to seek consensus on a preferred alternative. The task instructions, case overview, and possible solutions are included in Appendix A.

\section{Procedure}

The task and experimental procedures were pilot-tested among a separate sample of 32 participants from the same population organized into eight teams. The pilot test involved assessment of the procedures, technology, participant materials/instructions, appropriateness of the length of the e-profile, survey, task work, and overall length of the study. Only minor adjustments were made to the instructions to provide clarity. The survey, e-profiles, and team decisions were all examined to ensure that participants had adequate time to consider and respond appropriately.

Participants were randomly assigned to teams and teams were randomly assigned to either the treatment (e-profile exposure) or control condition (no e-profile exposure). In both conditions, members of each team were assigned to separate rooms, to simulate the distributed team experience. We developed an e-profile application designed to capture information from team members about their values and beliefs (deep-level attributes). The application was also designed to take the information supplied by each participant and display it to other team members. In their respective rooms, participants were instructed to complete the online profile, which had been pilot-tested for accuracy and length. Specifically, participants used the e-profile to provide information on 75 of their attributes (e.g., attitude toward and importance of education, cheating and fairness; ethical standards; punishment for cheaters; academic 
standards). All participants were given 10 minutes to complete their e-profile. The e-profile items are shown in Appendix B.

Upon completion of the e-profile, participants in the treatment condition (e-profile exposure) were then presented with a set of profile web pages containing information about their teammates. Specifically, each team member's web page showed his or her anonymous username, followed by a list of attributes about that member. Each participant in the treatment condition was only able to see the attributes of teammates that were similar to their own. To illustrate, in filling out her profile one team member, Sarah, indicated that she believes that instructors should have the highest ethical standards and also indicated that she participates in college athletics. In filling out his profile her teammate, John, indicated that he believes that instructors should have the highest ethical standards and that he does not participate in college athletics. When Sarah accessed John's profile, she would see that John believes that instructors should have the highest ethical standards, but she would not see information about participation in college athletics. The same would apply to John in viewing Sarah's profile. Participants in this condition were given 15 minutes to view the information about their teammates and explore this information on their own. During this time, participants in the control condition were not presented with information on their teammates. All participants were given word search puzzles unrelated to the task and told they could work on them at any point if they were waiting. To equalize the time across conditions, participants in the control condition were told they could work on the puzzles, while those in the treatment condition were told to review their teammate's e-profiles. Instead of viewing their teammates' e-profiles, the control condition saw a web page thanking them for providing their information.

All participants were then provided with case materials. All participants were given 10 minutes to read the case and think about the decisions they would make. Following this, all team members 
logged into a text-based chat application to perform the team judgment task. All teams were allocated 20 minutes to discuss the case and attempt to reach a consensus on each of the five issues. At the end of the 20 minutes, participants were given 5 minutes to record the team's final decisions. Finally, all participants completed a survey that assessed their perception of team conflict and shared understanding. They were then debriefed and dismissed.

\section{Measurement}

All of the items in the survey are from previously validated scales. Relational conflict, task conflict and shared understanding all represent team-level constructs. We surveyed individual team members to obtain measures for these constructs by using a referent shift consensus approach advocated by Chan (1998), where the team was used as the referent for questions about these constructs. In order to obtain a single team-level score for each of these variables, it was necessary to aggregate the responses of individuals within each team. However, to avoid creating biased estimates, it is important to ensure that such aggregation is justified. We accomplished this by examining three key aggregation statistics that are standard in team research: the within-group agreement index $\left(r_{w g(j)}\right)$, which represents the extent to which individual within-team ratings of a scale converge greater than would be expected by chance (James et al., 1984); the intraclass correlation coefficient ICC(1), which represents the variability in individual responses that is attributable to team membership, and the $\operatorname{ICC}(2)$, which represents the stability of the team-level means (Bliese, 2000). Aggregation was justified for all team-level constructs, thus we averaged the within-team responses to create team-level scores.

Relational conflict. We used a five-item scale developed by Jehn (1995) to measure relational conflict. The scale captures the extent to which tensions of an interpersonal nature are evident in the team and is measured on a five-point Likert-type scale $(1=$ none, $5=$ a great deal $)$. One sample item from this scale is, "How much emotional conflict was there among your team 
members?" The scale had a reliability of .95 . The mean $r_{w g(j)}$ was .98 and the ICC(1) and ICC(2) were .86 and .96 , respectively.

Task conflict. A three-item scale developed by Pelled et al. (1999) was used to measure task conflict. The scale reflects the extent to which disagreements about the task are evident in the team and is measured on a five-point Likert-type scale $(1=$ none, $5=$ a great deal). A sample item is, "How often did members of your team disagree about the decisions to be made?" The reliability of the scale was .91 . The mean $r_{w g(j)}$ for the scale was .96 and the $\operatorname{ICC}(1)$ and ICC(2) were .70 and .90 , respectively.

Shared understanding. We measured shared understanding with a five-item scale developed by Ko et al. (2005). The scale captures the extent to which members of the team have similar views on tasks, objectives and problem-solving approaches and is measured on a seven-point Likert-type scale ( $1=$ strongly disagree, $7=$ strongly agree). An item from this scale is "My teammates and I solve problems the same way." The reliability was .96 and the mean $r_{w g(j)}$ was .99. $\operatorname{ICC}(1)$ and $\operatorname{ICC}(2)$ were .50 and .79 , respectively.

Team effectiveness. Team effectiveness was assessed as a function of both quality and quantity of task performance. Because judgment tasks have no correct answer (Straus and McGrath, 1994), and in some cases no best answer, quality of task performance reflects teams' ability to follow a directive (e.g., in this case balancing the competing interests of those involved in the case). Following a directive in a judgment task requires teams to communicate the various facts of the case, as well as their own values, opinions, and beliefs and demonstrates their ability to coordinate their discussion and evaluate the merits of various solutions (Straus, 1999). Quantity of task performance reflects the team's ability to resolve conflicting viewpoints and negotiate among themselves in pursuit of consensus on multiple issues. 
To assess quality and quantity of task performance (i.e., team effectiveness), we used a scoring scheme developed by Straus and McGrath (Straus, 1992). The scoring scheme is composed of two sets of point values for each of the possible solutions to the five issues to be settled in the case. The first set of points reflects the degree to which that solution supports a given constituency's interests. The second set of points assigns a weight to the issue, which reflects its importance for a given constituency. The product of these two values (representing interest maximization and importance of the issue) produces a score for that particular issue. This value is calculated for each issue, and the five issues are summed across the three constituencies. Teams that do not reach consensus on an issue receive a zero for that issue (reflecting decision quantity). The final team effectiveness score is the product of scores for the athletic department, faculty, and administration. This procedure yields the highest team effectiveness score for those teams that choose a combination of solutions that balance the competing interests of the three constituencies (reflecting decision quality). This scoring scheme does not require team effectiveness to be rated and thus is independent of individual rater bias. Appendix $C$ shows the weights and point values used to calculate team effectiveness scores.

E-profile condition. We used a dummy variable to indicate whether a team was in the treatment condition in which the e-profile showed information on the deep-level attributes that were shared by team members or in the control condition in which no information was shown. Specifically, the e-profile dummy variable was coded 0 for the control condition and 1 for the treatment condition.

\section{Manipulation Check}

We performed a manipulation check to determine whether teams that were exposed to information about their deep-level similarities through e-profiles had significantly stronger perceptions of similarity than teams that were not. To assess whether the manipulation was 
effective, we used a five-item perceived deep-level diversity scale adapted from Harrison et al. (2002), given to participants before they started to work together on the task. ${ }^{2}$ The scale captures the extent to which individuals in a team believe they are similar or different from one another and is measured on a five-point Likert-type scale ( $1=$ very similar, $5=$ very different). Instructions for the scale told team members to rate the extent to which they feel they are similar to their teammates on certain deep-level attributes. A sample item is, "Please indicate how similar or different you and your teammates are in terms of your personal values." The scale had a reliability of .90 . Aggregated to the team level of analysis, the mean $r_{w g(j)}$ for the scale was .96 , and the $\operatorname{ICC}(1)$ and $\operatorname{ICC}(2)$ were .41 and .72 , respectively. Examination of the means for the two conditions suggests that the manipulation was effective, with teams in the treatment condition perceiving themselves to be less diverse (more similar) in their deep-level attributes compared to teams in the control condition: $M_{\text {treatment }}=3.08(S D=.61), M_{\text {control }}=3.73(S D=.54)$, $F=14.96(p<.001)$. Results at the individual level of analysis were highly similar. The mean perceived deep-diversity of participants in the treatment condition was significantly lower than that of participants in the control condition: $M_{\text {treatment }}=3.06(S D=.64), M_{\text {control }}=3.69(S D=.62)$, $F=42.51(p<.001)$.

One potential explanation for differences in shared understanding might be differences in actual deep-level diversity across treatment groups ${ }^{3}$. In other words, we wanted to ensure that it was the e-profile use that was influencing perceptions of deep-level similarity, rather than actual

\footnotetext{
${ }^{2}$ A possible limitation to asking participants about their perceptions of similarity prior to the task is alerting them to the study's purpose, which could impact their subsequent behavior. During the debriefing at the end of the study we inquired into participants' guesses about the purpose of the study. No participants were able to determine the exact purpose of the study; the typical guesses focused on the nature of computer-mediated communication on team functioning. Very few participants mentioned the e-profiles.

${ }^{3}$ Per the guidelines of Harrison and Klein (2007), deep level differences were measured as the within-team standard deviation of member's responses to the 75 questions.
} 
differences in deep-level similarity between the treatment groups. To examine this issue, we used the data supplied through the participants' e-profiles to represent actual or objective deeplevel similarity and tested for differences across treatment conditions. Actual deep-level similarity was not correlated with the dummy variable representing treatment groups, suggesting that there was no significant difference in actual deep-level similarity across treatment groups $\left(\mathrm{M}_{\text {treatment }}=.51, \mathrm{M}_{\text {control }}=.63, \mathrm{~F}=1.38, \mathrm{p}>.10\right)$. Thus, we conclude that the use of the e-profiles, rather than differences in actual deep-level similarity, was what influenced perceptions of deeplevel similarity.

Finally, random assignment of participants to teams and random assignment of teams to the experimental conditions minimized the need for control variables. Nonetheless, we collected data on several standard demographic and team compositional variables as an additional check on randomization. Age, gender, marital status, racial diversity, and team size were examined across the two conditions. No statistical differences in means were found between teams in the treatment and control conditions. Moreover, in examining the correlations between these variables and our constructs of interest (i.e., relational and task conflict, shared understanding, and team effectiveness), as well as their limited predictive value in simple regression models, we decided they did not warrant inclusion in our analysis.

\section{Analysis and Results}

The data were analyzed using a partial least squares (PLS) approach and the software SmartPLS version 2.0. PLS is a component-based structural equation modeling technique that aims to maximize the variance explained in the dependent latent variables. PLS was chosen because it is well-suited for testing structural models such as the one reflected in our research model and is particularly appropriate for theory building (as opposed to theory testing) (Hair et al., 2011), as is the case with our model. The generally accepted guideline for robust PLS path 
modeling estimations suggests that the sample size be the equal to the larger of the following: (1) ten times the number of items of the scale with the largest number of formative indicators, or (2) ten times the largest number of structural paths directed at a particular construct (Barclay et al., 1995; Hair et al., 2011). Because there are no formative indicators in our model, we applied the second guideline to determine whether PLS was appropriate for our sample. The largest number of structural paths directed at any construct in our hypothesized model is three, thus the minimum sample size would be 30 , and our sample size of 46 teams surpasses this threshold.

With PLS, the measurement model and structural model are produced simultaneously. First, we proceed with examination of the measurement model, followed by examination of the structural model. Relational conflict, task conflict, and shared understanding were each modeled as reflective constructs consistent with prior research and were assessed for validity. Construct validity is achieved when acceptable measures of convergent and discriminant validity are observed (Hair et al., 2006). Convergent validity can be assessed by analyzing the average variance extracted (AVE), internal composite reliability (ICR), Cronbach's alpha, and factor loadings. Table 1 provides AVE, ICR, and Cronbach's alpha values. Each of the AVE values should be greater than .50 and all constructs met this criterion (Chin, 1998). Additionally, all of the values for Cronbach's alpha and ICR were larger than .70, demonstrating internal consistency (Fornell and Larcker, 1981). Table 2 shows the construct loadings and crossloadings for the multi-item latent constructs. The standardized factor loadings shown in Table 2 are greater than .70, indicating appropriate convergence of items to their factors (Hair et al., 2006).

\section{Table 1: Psychometric Measurement Validation}

\begin{tabular}{|l|c|c|c|}
\hline & AVE & ICR & $\begin{array}{c}\text { Cronbach's } \\
\text { alpha }\end{array}$ \\
\hline Relational conflict & .84 & .96 & .95 \\
\hline Task conflict & .85 & .95 & .91 \\
\hline Shared understanding & .87 & .97 & .96 \\
\hline
\end{tabular}


Discriminant validity refers to the extent to which a construct is truly distinct from the other constructs and often is assessed according to whether the cross-loadings on a given factor are below .40 (Straub et al., 2004). Table 2 shows that this was not the case for task conflict and shared understanding, requiring a more in-depth assessment of discriminant validity. This is not surprising given the high correlation between these variables (-.57). Gefen and Straub (2005, p. 93-94) suggest that when using PLS and assessing discriminant validity, "all the loadings of the measurement items on their assigned latent variables should be an order of magnitude larger than any other loading. For example, if one of the measurement items loads with a .70 coefficient on its latent construct, then the loadings of all the measurement items on any latent construct but their own should be below .60." This was the case with our model, but we thought further assurance was needed. We performed an exploratory factor analysis (EFA) using a principal components method. By allowing the factor structure to vary and rotating the component matrix (using a varimax rotation), we observed a clean three-factor structure with all cross-loadings below .35, providing support for discriminant validity. This is shown in Table 3.

\begin{tabular}{|r|c|c|c|}
\hline \multicolumn{5}{|c|}{$\begin{array}{c}\text { Relational } \\
\text { conflict }\end{array}$} & $\begin{array}{c}\text { Shared } \\
\text { understanding }\end{array}$ & $\begin{array}{c}\text { Task } \\
\text { conflict }\end{array}$ \\
\hline Average relational conflict1 & .88 & & \\
\hline Average relational conflict2 & .96 & & \\
\hline Average relational conflict3 & .96 & & \\
\hline Average relational conflict4 & .96 & & \\
\hline Average relational conflict5 & .83 & & \\
\hline Average shared understanding1 & & .94 & -.58 \\
\hline Average shared understanding2 & & .89 & -.48 \\
\hline Average shared understanding3 & & .94 & -.61 \\
\hline Average shared understanding4 & & .95 & -.48 \\
\hline Average shared understanding5 & & .95 & -.48 \\
\hline Average task conflict1 & & -.52 & .87 \\
\hline Average task conflict2 & & -.50 & .95 \\
\hline Average task conflict3 & & -.54 & .94 \\
\hline
\end{tabular}

Note: Factor loadings smaller than .40 or greater than -.40 are not displayed to improve readability. Item scores were averaged within teams. 
Table 3: Exploratory Factor Analysis Loadings and Cross-loadings

\begin{tabular}{|r|c|c|c|}
\hline & $\begin{array}{c}\text { Relational } \\
\text { conflict }\end{array}$ & $\begin{array}{c}\text { Shared } \\
\text { understanding }\end{array}$ & $\begin{array}{c}\text { Task } \\
\text { conflict }\end{array}$ \\
\hline Average relational conflict1 & .86 & & \\
\hline Average relational conflict2 & .96 & & \\
\hline Average relational conflict3 & .95 & & \\
\hline Average relational conflict4 & .96 & & \\
\hline Average relational conflict5 & .86 & & \\
\hline Average shared understanding1 & & .88 & \\
\hline Average shared understanding2 & & .87 & \\
\hline Average shared understanding3 & & .88 & \\
\hline Average shared understanding4 & & .94 & \\
\hline Average shared understanding5 & & .93 & \\
\hline Average task conflict1 & & & .83 \\
\hline Average task conflict2 & & & .91 \\
\hline Average task conflict3 & & & .87 \\
\hline
\end{tabular}

Note: Factor loadings smaller than .40 or greater than -.40 are not displayed to improve readability. Item scores were averaged within teams.

As an additional check, we followed Fornell and Larcker's (1981) recommendation for assessing discriminant validity by comparing the square root of the AVE to the correlations among the variables. According to this approach, if the square root of the AVE is higher than the correlations among variables, discriminant validity is upheld. Table 4 shows the correlation matrix with the square root of the AVE on the diagonal of the matrix; all constructs meet this criterion. This assessment provides additional assurance that, though task conflict and shared understanding are highly correlated, participants were able to discriminate between them.

Before we turned to assessment of the structural model, we further examined the descriptive statistics and performed a series of mean comparisons via an analysis of variance, as a preliminary check of our experimental manipulation. The result of this analysis is shown in Table 5. Examination of treatment and control group means, at both the individual and team levels of analysis, shows remarkable consistency. Specifically, mean levels of relational conflict are not statistically different between the treatment and control groups. Mean levels of task conflict, 
however, are significantly lower for the treatment group compared to the control group, while shared understanding is significantly higher for the treatment group teams. As can be seen below, these findings are congruent with the results observed when we examined the structural model. E-profile use lowered task conflict and increased shared understanding but did not affect relational conflict.

\section{Table 4: Descriptive Statistics and Correlations Among Constructs}

\begin{tabular}{|l|r|r|c|c|c|c|c|}
\hline & Mean & S.D. & 1 & 2 & 3 & 4 & 5 \\
\hline 1. e-profile use & .50 & .50 & NA & & & & \\
\hline 2. Relational conflict & 3.20 & .91 & -.20 & .92 & & & \\
\hline 3. Task conflict & 2.89 & .67 & $-.64^{* *}$ & .08 & .92 & & \\
\hline 4. Shared understanding & 4.73 & .93 & $.60^{\star *}$ & -.16 & $-.57^{* *}$ & .93 & \\
\hline 5. Team effectiveness & $4,441.24$ & $2,903.72$ & $.54^{\star *}$ & $-.46^{* *}$ & $-.43^{* *}$ & $.66^{* *}$ & NA \\
\hline
\end{tabular}

Note: $\mathrm{N}=46$; Values on the diagonals represent the square root of the AVE for each factor.

${ }^{*} p<.05,{ }^{* *} p<.01$. "e-profile use" represents the experimental condition $(0=$ control condition, $1=$ treatment condition).

To assess the significance of the paths of the structural model, we used the standard bootstrap resampling procedure in SmartPLS, using 1,000 resamples. To ensure that multicollinearity was not influencing the results, we used the latent variable scores from the PLS analysis to produce variance inflation factors (VIFs). At 2.03, the highest VIF was well below the commonly accepted threshold of 10 , indicating that multicollinearity was unlikely to influence the results. Figure 2 shows the model results, displaying the variance explained $\left(R^{2}\right)$ and the standardized path coefficients $(ß)$ of the structural model. Overall, the model explained a moderate amount of the variance in three of the latent constructs (task conflict $R^{2}=.41$, shared understanding $R^{2}=$ .33 , and team effectiveness $R^{2}=.43$ ) and very little in another (relational conflict $R^{2}=.04$ ).

As the results in Figure 2 indicate, we received support for a majority of the hypothesized relationships in the model. $\mathrm{H} 1$ hypothesized a negative relationship between the e-profile 


\begin{tabular}{|c|c|c|c|c|c|c|c|c|c|c|c|c|c|c|}
\hline & \multicolumn{4}{|c|}{ Combined Sample } & \multicolumn{5}{|c|}{ Individual-level Split Sample } & \multicolumn{5}{|c|}{ Team-level Split Sample } \\
\hline & \multicolumn{2}{|c|}{$\begin{array}{c}\text { Individual-level } \\
n=169\end{array}$} & \multicolumn{2}{|c|}{$\begin{array}{c}\text { Team-level } \\
n=46\end{array}$} & \multicolumn{2}{|c|}{$\begin{array}{c}\text { Treatment } \\
n=82\end{array}$} & \multicolumn{2}{|c|}{$\begin{array}{c}\text { Control } \\
\mathrm{n}=87\end{array}$} & \multirow[t]{2}{*}{$\mathrm{F}$} & \multicolumn{2}{|c|}{$\begin{array}{c}\text { Treatment } \\
n=23\end{array}$} & \multicolumn{2}{|c|}{$\begin{array}{c}\text { Control } \\
n=23\end{array}$} & \multirow[t]{2}{*}{$\mathrm{F}$} \\
\hline & Mean & S.D. & Mean & S.D. & Mean & S.D. & Mean & S.D. & & Mean & S.D. & Mean & S.D. & \\
\hline Relational conflict & 3.16 & .94 & 3.20 & .91 & 3.03 & .93 & 3.29 & .94 & 3.03 & 3.07 & .89 & 3.34 & .93 & 1.01 \\
\hline Task conflict & 2.87 & .74 & 2.89 & .67 & 2.46 & .61 & 3.31 & .61 & $83.06^{* *}$ & 2.47 & .54 & 3.31 & .49 & $30.53^{* *}$ \\
\hline Shared understanding & 4.72 & 1.14 & 4.73 & .93 & 5.27 & .95 & 4.14 & 1.04 & $55.22^{* *}$ & 5.28 & .55 & 4.17 & .90 & $26.61^{* *}$ \\
\hline
\end{tabular}

Note: ${ }^{*} p<.05,{ }^{* *} p<.01$.

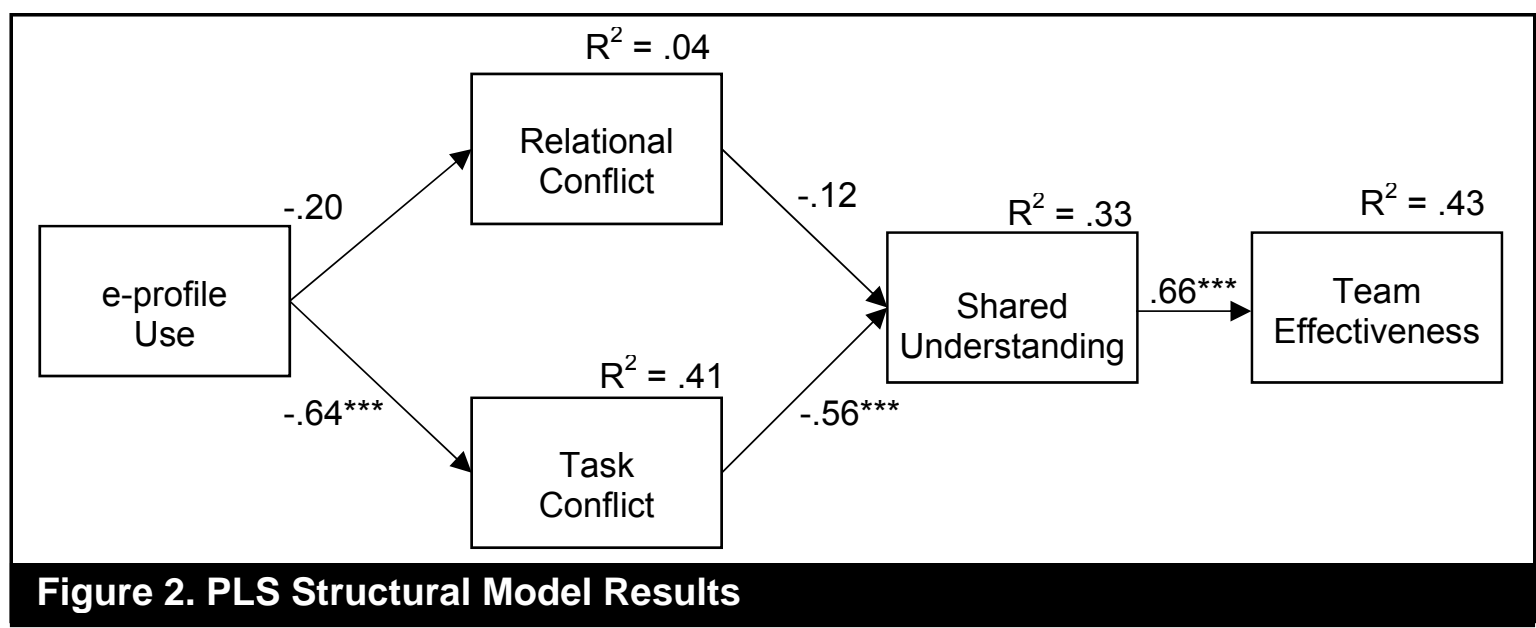

Note: $\mathrm{N}=46 ;{ }^{*} \mathrm{p}<.05,{ }^{* *} \mathrm{p}<.01,{ }^{* * *} \mathrm{p}<.001$. 
condition and relational conflict. Although the sign is in the expected direction, this relationship is not supported $(\beta=-.20, p>.10)$. $\mathrm{H} 2$ predicted that the e-profile condition would negatively influence task conflict. This hypothesis receives support $(\beta=-.64, \mathrm{p}<.001)$. In H3 and H4, we predicted that relational conflict and task conflict would negatively influence shared understanding. The results show that task conflict $(\beta=-.56, p<.05)$ reduces shared understanding, providing support for $\mathrm{H} 4$. However, $\mathrm{H} 3$ does not receive support $(\beta=-.12, p>$ .10). H5 predicted that shared understanding would positively impact team effectiveness, and this was supported $(\beta=.66, p<.001)$. A summary of the findings is shown in Table 6 .

\section{Table 6: Summary of Hypotheses and Results}

\begin{tabular}{|l|l|l|}
\hline \multicolumn{2}{|l|}{ Hypotheses } & Finding \\
\hline $\mathrm{H} 1$ & $\begin{array}{l}\text { Exposure to information on the deep-level similarities of } \\
\text { team members will negatively influence relational conflict in } \\
\text { distributed teams. }\end{array}$ & Not supported \\
\hline $\mathrm{H} 2$ & $\begin{array}{l}\text { Exposure to information on the deep-level similarities of } \\
\text { team members will negatively influence task conflict in } \\
\text { distributed teams. }\end{array}$ & $\begin{array}{l}\text { Supported } \\
\text { Relational conflict will negatively influence shared } \\
\text { understanding in distributed teams. }\end{array}$ \\
\hline H3 & $\begin{array}{l}\text { Task conflict will negatively influence shared understanding } \\
\text { in distributed teams. }\end{array}$ & Supported \\
\hline H5 & $\begin{array}{l}\text { Shared understanding will positively influence the } \\
\text { effectiveness of distributed teams }\end{array}$ & Supported \\
\hline
\end{tabular}

\section{Post Hoc Analysis}

In addition to testing our hypothesized relationships, we performed a post hoc analysis to examine the data for possible mediated relationships that could shed further light on our model. To do this, we followed the procedures recommended by Preacher and Hayes (2008). The Preacher and Hayes $(\mathrm{PH})$ approach is recommended for multiple mediator models, as is the case with our model. In addition, it addresses the limitations associated with causal step 
approaches, e.g., Baron and Kenny (1986), which have increasingly been called into question in recent years (e.g., Preacher and Hayes, 2008; Rucker et al., 2011; Zhao et al., 2010). The PH approach employs a bootstrapping technique to estimate the total and direct effects of the independent variables on the dependent variables and the indirect effects through the mediator. This involves repeated resampling (1,000 in the current study) of the dataset to estimate total, direct, and indirect effects and confidence intervals $(\mathrm{Cl})$ for the indirect effects. Unlike causal step approaches, the $\mathrm{PH}$ approach does not distinguish between partial and full mediation but rather focuses on the comparative strength and significance of the indirect effect. In fact, due to the implications for theory yet dependence on sample size, the meaningfulness of distinguishing between partial and full mediation has been questioned (Rucker et al., 2011; Zhao et al., 2010).

The mediation analysis using the $\mathrm{PH}$ approach is shown in Table 7 . The coefficients for total and direct effects show the relative proportion of the influence of the independent variable on the dependent variable that is caused by direct versus total effects (i.e., direct and indirect effects), while the accompanying t-values indicate the significance of these relationships. To evaluate the analysis in light of the mediated relationships in our model, we examined the values under the heading of "Indirect Effects," specifically, the bias-corrected Cl shown at the far right of Table 7 . These values allow us to assess the reliability of the point estimates generated by the bootstrap procedure and are corrected for bias by adjusting the interval for deviation between the original sample value and the mean of the bootstrap value. This generates a more accurate $\mathrm{Cl}$. An indirect effect is significant if the $\mathrm{Cl}$ does not include zero.

First, we examined the $\mathrm{Cl}$ for a mediated relationship between e-profile use and shared understanding via relational conflict and task conflict, shown in Model 1 of Table 7 . The $\mathrm{Cl}$ for relational conflict contains zero (-.04 to .19), while the $\mathrm{Cl}$ for task conflict does not contain zero (.01 to .82). Thus, the indirect effect of e-profile use on shared understanding is carried through 
task conflict only. Next, we examined the impact of relational conflict on team effectiveness mediated through shared understanding. Model 2 in Table 7 shows that the $\mathrm{Cl}$ for the mediator contains zero (-590.91 to 312.98$)$, thus shared understanding does not indirectly affect team effectiveness via relational conflict. Finally, we examined whether the impact of task conflict on team effectiveness would be mediated by shared understanding. Model 3 in Table 7 shows that the $\mathrm{Cl}$ for the mediator does not contain zero $(-2,134.58$ to -665.29$)$, thus demonstrating that task conflict has an indirect effect on team effectiveness via shared understanding ${ }^{4}$.

\section{Table 7: Mediation Hypotheses Tests}

\begin{tabular}{|c|c|c|c|c|c|c|c|c|}
\hline \multicolumn{2}{|c|}{$\begin{array}{l}\text { Total Effect } \\
\text { of IV on DV }\end{array}$} & \multicolumn{2}{|c|}{$\begin{array}{l}\text { Direct Effect } \\
\text { of IV on DV }\end{array}$} & \multicolumn{5}{|c|}{ Indirect Effects } \\
\hline Coefficient & T-value & Coefficient & T-value & & & $\begin{array}{c}\text { Point } \\
\text { Estimate }\end{array}$ & \multicolumn{2}{|c|}{$\mathrm{BC} 95 \% \mathrm{Cl}$} \\
\hline \multicolumn{9}{|c|}{ Model 1: Shared Understanding as the DV, E-profile Use as the IV } \\
\hline \multirow{3}{*}{1.12} & \multirow{3}{*}{5.09} & \multirow{3}{*}{.75} & \multirow{3}{*}{2.66} & \multicolumn{2}{|c|}{ Total Indirect Effects } & .36 & .01 & .84 \\
\hline & & & & \multirow{2}{*}{ Mediator } & $\begin{array}{l}\text { Relational } \\
\text { Conflict }\end{array}$ & .01 & -.04 & .19 \\
\hline & & & & & $\begin{array}{c}\text { Task } \\
\text { Conflict }\end{array}$ & .35 & .01 & .82 \\
\hline \multicolumn{9}{|c|}{ Model 2: Team Effectiveness as the DV, Relational Conflict as the IV } \\
\hline$-1,386.41$ & 3.59 & $-1,207.20$ & 3.71 & Mediator & $\begin{array}{c}\text { Shared } \\
\text { Understanding }\end{array}$ & -179.21 & -590.91 & 312.98 \\
\hline \multicolumn{9}{|c|}{ Model 3: Team Effectiveness as the DV, Task Conflict as the IV } \\
\hline$-1,780.77$ & 3.38 & -441.71 & 83 & Mediator & $\begin{array}{c}\text { Shared } \\
\text { Understanding }\end{array}$ & $-1,339.07$ & $-2,134.58$ & -665.29 \\
\hline
\end{tabular}

Notes: IV=independent variable, $\mathrm{DV}=$ dependent variable, $\mathrm{BC}=$ bias-corrected, $\mathrm{Cl}=$ confidence interval; In models 2 and 3 , task conflict and relational conflict, respectively, were added as covariates.

\section{Discussion}

Despite the widespread use of distributed teams, we lack insight into how such teams can

\footnotetext{
${ }^{4}$ To provide an additional check of the mediation, we examined the relationships according to Baron and Kenny's (1986) causal steps approach. The results are provided in Appendix C and the pattern supports the results observed using Preacher and Hayes' (2008) approach.
} 
achieve shared understanding. Using SCT as a foundation, the purpose of this research was to present and test a model of how a technological intervention (e-profiles) that reveals team members' similar deep-level attributes could be leveraged to facilitate shared understanding in distributed teams. Our findings indicate that e-profiles can reduce task conflict. In addition, we found that task conflict reduces shared understanding in distributed teams and that shared understanding positively impacts team effectiveness. Relational conflict had no impact on teams' level of shared understanding, though it did have a negative, direct impact on team effectiveness (Model 2, Table 7). Overall, our results are a first step toward demonstrating the effectiveness of using a technological intervention like e-profiles to improve outcomes for distributed teams.

This research makes several contributions to the IS literature on distributed teams. First, research has highlighted how technology-mediated communication tends to increase conflict (Griffith et al., 2003a; Polzer et al., 2006) and decrease shared understanding within teams (Hinds and Bailey, 2003; Kankanhalli et al., 2007). However, little if any research has been devoted to understanding how technology can be leveraged to address these issues and facilitate effective team collaboration. In this study, we found that a simple, formal intervention can reduce task conflict in distributed teams. Thus, we contribute to the literature that recognizes the role that technology-based socialization mechanisms play in facilitating positive team collaborations (Carte and Chidambaram, 2004; Maruping and Agarwal, 2004). In particular, this research complements the work of Carte and Chidambaram (2004) in suggesting that the pitfalls of diversity can be overcome by leveraging technology that suppresses surface characteristics (e.g., the teams in our sample never met face-to-face and did not have information about one another's age, gender, race, etc.). 
We extend this idea of leveraging technology to focus on the deep-level characteristics that team members share. In doing so, we illustrate how technology may be applied to influence human behavior. Exploration of interventions aimed at socialization represents an important direction for distributed team research, because having information about one's teammates has been shown to influence the attributions that are made about others' input during collaboration (Vignovic and Thompson, 2010). When we consider that teams that used e-profiles were no more or less similar in the make-up of their deep-level attributes than teams that did not use eprofiles, we can begin to see the potential role that technology can play in reducing conflict, promoting shared understanding, and increasing effectiveness in distributed teams. We believe this method of reducing task conflict and facilitating both a shared understanding and team effectiveness represents a novel approach to addressing the problems associated with SCT. Therefore, this study extends the literature on team diversity by arguing that in-group/out-group categorization derived through SCT can be channeled productively through the use of a technological intervention. Moreover, we leverage a technological intervention to demonstrate that team members who believe they are similar in deep-level attributes are more effective in performing a judgment task than those who do not hold such beliefs.

Second, this research contributes to the IS literature by uncovering the theoretical mechanisms by which emphasizing deep-level similarities (through e-profile use) can translate into improved effectiveness in distributed teams. We examined how technology was successfully leveraged to shape the relationships between task conflict and shared understanding. This study provides and empirically tests a nomological network using SCT as the theoretical foundation depicting the relationships between e-profile use, conflict, shared understanding and team effectiveness in distributed teams. The results of this study demonstrate that the effects of e-profile use on shared understanding are mediated by task conflict, and the impact of task conflict on team effectiveness is mediated through shared understanding. 
Third, this research contributes to the literature on conflict in distributed teams by uncovering important differences in the antecedents and impacts of relational and task conflict. Although we found that the e-profile intervention was effective in explaining task conflict $\left(R^{2}=.41\right)$ it was quite poor in predicting relational conflict $\left(R^{2}=.03\right)$. This is surprising because one might expect that creating feelings of deep-level similarity among team members would reduce feelings of dislike, and therefore influence relational conflict. One would also assume that relational conflict would decrease shared understanding; however, once again this simply was not the case. Two potential theoretical explanations for why e-profile use did not explain much variance in relational conflict and why relational conflict was not a significant predictor of shared understanding are: 1) the short duration of the interaction may have contributed to a sense of exigency in completing the task; and 2) distributed teams have a tendency to be highly taskfocused (Martins et al., 2004). These factors may have resulted in teams being more attuned to factors that might impede progress (e.g., task conflict) than they were on negotiating interpersonal relationships as they worked to build a shared understanding of the task. Research on face-to-face teams suggests that visible dissimilarity is a key trigger for relational conflict (Jehn et al., 1997). It is possible that teams in our study were missing a key trigger (visual cues) of relational conflict. However, such explanations do not account for the finding that relational conflict was a strong predictor of team effectiveness, as shown in the post hoc analysis (Model 2, Table 7). It may be that the antecedents and impacts of relational conflict in distributed teams are different from those of task conflict. Additional research exploring the antecedents of task, and especially relational conflict, are required to tease out these nuanced effects. Another possibility, however, is that our instrument was not sensitive enough to detect relational conflict. We discuss this further in the limitation section.

We also contribute to the conflict literature by being among the first to identify one of the mechanisms by which conflict impacts team effectiveness. Research on conflict in teams 
typically links conflict directly to team effectiveness (De Dreu and Weingart, 2003; de Wit et al., 2012). Our results show that shared understanding can be an important mediator of the conflicteffectiveness relationship. Research shows that conflict has mixed impacts on team effectiveness and related outcomes (Jehn, 1997; Jehn et al., 1999; Pelled, 1996; Pelled et al., 1999). Identifying the mediating mechanisms that account for the impact of conflict on team effectiveness can help us better understand these mixed effects. Moreover, examination of such mechanisms is important considering the different contextual experiences of teams. We theorize that shared understanding is a particularly relevant mechanism among distributed teams, given their difficulty with communication, integration, and lack of shared experience. Other mechanisms may be particularly important for other types of teams and contexts and warrant further study.

Fourth, the current study demonstrates that distributed contexts have important implications for team work and human behavior, based on SCT. For example, Ensley and Pearce (2001), examined the impact of cognitive conflict (similar to task conflict) in face-to-face teams. Consistent with our observations, they found that cognitive conflict was a significant predictor of shared understanding within teams. However, in their study cognitive conflict was positively related to teams reaching a shared understanding. Our findings extend this work to an increasingly important context, that of distributed teams. Although there are several differences between their work and ours (e.g., lab vs. field experiment), in light of the corpus of research on the role of communication media in influencing team processes and interpersonal relationships (Maruping and Agarwal, 2004), it is likely that the distributed context may influence the impact of cognitive conflict on shared understanding. Using SCT as the foundation for understanding cognitive processes and human behavior, additional research is needed to explore the relationships between technological interventions, task conflict, and shared understanding. Although further research is needed to compare face-to-face teams with distributed teams, the 
current study represents a point of departure for examining such differences. Further research should be conducted to explicate the similarities and differences of the impact of an e-profile presented a priori to the first encounter of both face-to-face and distributed teams.

\section{Limitations}

The potential limitations associated with the use of student subjects in a laboratory setting are well established (Colquitt, 2008). Of chief concern are questions related to external validity. It should be noted, however, that the purpose of a lab study is to enhance internal validity, not external validity. This allows researchers to draw causal inferences that may be difficult or impossible to accomplish in a field setting (Colquitt, 2008; Ilgen et al., 2005). Nonetheless, researchers do not generalize from study to study but from study to theory (Lee and Baskerville, 2003). As such, we believe our theoretical justifications would be consistent in another setting; however, further work is required to determine whether organizational teams can benefit from the use of e-profiles. Furthermore, we have included an assessment of parallelism, limitations and consistency between elements as recommended when using student subjects (Compeau et al., 2012). In particular, because of the constraints of a laboratory study, the duration of interaction among team members was somewhat limited (approximately 30 minutes). It is possible that longer periods of interaction would erode the effect of the manipulation as team members exchange information that reveals differences among them. However, research shows that individuals tend to form impressions of others based on initial exposure and that they make only minor adjustments to that impression over time (Epley and Gilovich, 2006; Tversky and Kahneman, 1974). This tendency to use an anchoring-and-adjustment heuristic leads us to believe that the effects we observed could persist over time for organizational teams, although it is likely to attenuate. Additional research is needed to determine how long such effects endure. Moreover, in light of our sample size (46 teams) care should be taken in interpreting the results. 
Due to the limited sample size, low power precluded us from detecting whether e-profiles can reduce relational conflict and whether relational conflict reduces shared understanding. In fact, given that the correlation between e-profile use and relational conflict was nearing significance $(-.20, p<.10)$, it is possible that this could be significant given a larger sample size.

Given our experimental design, measurement and analysis, we are unable to completely rule out threats to internal validity from common method bias. Nearly all of our measures came from a common source (i.e., team members) and common method (i.e., survey). Our outcome measure (i.e., team effectiveness) was not taken from team members or the surveys they completed, helping to alleviate this concern to some extent. Nevertheless, multiple sources for assessing conflict, shared understanding and team effectiveness (e.g., chat transcript analysis, expert ratings of performance), would provide more assurance that common method bias did not influence our results. Moreover, although our path model implies causation, the timing of measurement of many key constructs (i.e., after teams worked together) precludes us from ruling out the possibility that shared understanding drove the occurrence of conflict, for example, as opposed to the directionality we argue. Without measurement of team processes as they unfolded our results demonstrate correlation while causality can only be implied via our theoretical arguments.

Measurement choices might also limit the results of this research. Recent research argues that group-level phenomena should be measured at the group level rather than measured at the individual level and aggregated to the group level (e.g., as we did with team conflict and shared understanding) (Sarker and Valacich, 2010). This perspective criticizes methodological individualism as a reductionist approach that overlooks important variance between group members and treatment of individual perceptions as reflective of group perceptions. Although we acknowledge this as a limitation of the study, we are reasonably comfortable that our use of 
the aggregation approach does not compromise our findings. Team conflict constitutes a shared team property (Klein and Kozlowski, 2000). Like other shared team properties, it originates from experiences and behaviors that are held in common by members of a team. The participants in our sample were in high agreement about their responses to questions about their group's conflict (as reflected in the average $r_{w g(j)}$ of .98 and .96 for relational and task conflict, respectively), supporting the notion that they all had a common experience of conflict within their respective teams. This is due to the fact that they are each reporting on behaviors (i.e., conflict) that they observed within their respective teams. Were there some discrepancy among team members in their assessment of conflict, this would manifest itself in low $r_{w g(j)}$ values (Klein and Kozlowski, 2000). We believe some potentially interesting insights can be gained by using a consensus approach to assessing conflict. An interesting future research direction would involve examination of variance in team members' perceptions of conflict and shared understanding, in the same vein as recent work on conflict asymmetry (Jehn et al., 2010). A multilevel perspective that incorporates both individual- and team-level perceptions of conflict and shared understanding could also yield important insights on the interplay between individual experiences and the collective experience of the group.

Another limitation related to measurement pertains to our finding that e-profiles did not affect relational conflict and relational conflict did not affect shared understanding. Although we provide some possible theoretical reasons for these findings and we did observe relational conflict to positively influence team effectiveness, we cannot rule out limitations or effects from the measurement of relational conflict. It is possible that the relational conflict that did exist was not well captured by the measure we used. The items for relational conflict tap into concepts like tension, friction, upset and personality clashes. These are interpersonal, emotionally laden concepts and it is possible they are too strong to capture the subtlety of relational conflict that occurs among strangers who do not meet face-to-face and who use only text-based tools to 
communicate. Methodologically, this could mean that we need to explore refinement of the measurement of relational conflict for distributed teams. The interesting theoretical implication is that relational conflict may unfold and be experienced very differently within distributed teams and co-located teams. We encourage further research on the nature and measurement of relational conflict in this context.

Our random assignment of participants to teams was such that specific elements of diversity within and across teams could be different. In other words, team members in the treatment condition saw different deep-level similarities about one another. Although this is a potential limitation of the design, researchers have little control over specific differences and similarities among participants, particularly in a randomized experiment. This is a common issue in studies of diversity. Moreover, literature suggests that it is not especially consequential from the standpoint that people who perceive similarities on one set of values are likely to assume that similarities exist on another set of values as well. This assumption shapes overall perceptions of similarity.

\section{Future Research}

Future research is needed to investigate the role technology plays in affecting the relationship between conflict and shared understanding. The type and timing of team conflict and whether it is beneficial for team effectiveness has long been debated (Jehn, 1997; Pelled, 1996; Pelled et al., 1999). Understanding the role of technology may provide additional insight into this question. Indeed, Maruping and Agarwal (2004) suggest that different technological capabilities can affect the extent to which conflict affects team outcomes at different points in time. Future studies should explore the circumstances in which it is beneficial or detrimental to focus attention on shared attributes in distributed teams. For example, in teams with a high degree of perceived similarity, team members may avoid challenging or debating alternative courses of 
action with teammates. However, conflict may lead to higher-quality team discussions and eventually higher team effectiveness. In this sense, certain levels of conflict may be beneficial for team effectiveness, particularly for certain types of tasks. Our results are limited to the judgment task that we examined. An interesting direction for future research would also involve exploration of conflict management strategies. It is possible that the relationship between task conflict and shared understanding is contingent upon the team's ability to manage conflict, with task conflict having positive implications for shared understanding if conflict is appropriately managed.

In this study, we found that task conflict was negatively related to shared understanding and team effectiveness. We believe our results may warrant additional investigation into conflict and distributed teams. However, in light of the recent developments surrounding the relationship between task conflict and team effectiveness we believe our results warrant a more detailed discussion relative to previous research on task conflict and team effectiveness (de Wit et al., 2012). First, two meta-analyses (De Dreu and Weingart, 2003; de Wit et al., 2012) determined that the degree of correlation between relationship and task conflict helped to determine whether task conflict would be positively or negatively related to team effectiveness. If task conflict was strongly, positively correlated with relationship conflict we could expect task conflict to be negatively related to team effectiveness, and if task conflict was not related to relationship conflict we could expect task conflict to be more positively related to team effectiveness or be unrelated to team effectiveness. However, with a correlation of $.05(p>.05)$ task conflict was not related to relationship conflict in our study. Second, de Wit et al. (2012) discovered that task conflict was more likely to be positively related to team effectiveness in student teams performing a specific task that had objectively measurable outcomes and that task conflict was likely to be negatively related to team effectiveness for teams in field studies with outcomes that 
were less specific and were measured more subjectively. Yet, our study examined student teams performing a specific task with objectively measureable outcomes.

As we mentioned earlier in the discussion section, our study differs from many of the studies in both meta-analyses in that we examined distributed teams rather than co-located teams. De Wit et al. (2012) did include studies examining conflict in distributed teams; however, there were not enough studies to use any type of measure of distribution as a potential moderator in the metaanalysis. As such, the impact that team distribution may have on the relationship between various types of conflict and team outcomes is still unclear. Research should investigate the influence of team distribution on both the development of team conflict and how it may alter the effects of team conflict.

Finally, in light of the problem associated with groupthink, future studies should explore the circumstances in which it is beneficial or detrimental to focus attention on shared attributes in distributed teams. For example, teams with a high degree of perceived similarity are more likely to engage in groupthink. This may, in turn, lead team members to avoid challenging their teammates' ideas or debating alternative courses of action with teammates (Janis, 1982). This also implies that teams could have too much shared understanding. When this happens, conflict may lead to higher-quality team discussions. In this sense, certain levels of conflict may be beneficial for team effectiveness, particularly for certain types of tasks, such as idea generation. Although our results are limited to the judgment task that teams performed in this study, future studies might examine the tradeoff between shared understanding and groupthink.

\section{Practical Implications and Conclusions}

Organizations are increasing their use of distributed teams, so the ability to manage these teams has become important (Lipnack and Stamps, 1997; Powell et al., 2004; Robert et al., 2008). Helping team members to reach a shared understanding of the team and its task, across 
distance, time and culture, may prove to be a key factor in the successful management of distributed teams (Maznevski and Chudoba, 2001; Niederman and Tan, 2011). E-profiles may offer managers an effective and low-cost formal intervention to aiding these teams by providing them with a mechanism to help them socialize and build shared understanding. Research has suggested that an initial face-to-face meeting may be necessary to help promote socialization in technology-enabled teams (Gibson and Manuel, 2003; Martins et al., 2004). This can be problematic for two reasons. One, such meetings require time and money, and although this may have seemed reasonable when only a handful of projects were handled by technologyenabled teams, with the amount of work done by such teams today it would be unrealistic to expect organizations to set up an initial face-to-face meeting for every team. Two, an initial faceto-face meeting may highlight surface-level differences (e.g., race, age) before team members have had an opportunity to form positive impressions of one another based on deep-level attributes. In contrast, enabling team members to see information about their teammates (specifically shared beliefs, values and attitudes) can help create a sense of solidarity. The electronic tools for disseminating such information among team members are commercially available and may enable managers to facilitate and control the initial information made available by team members.

Organizations invest significant resources into training employees to value diversity (Kochan et al., 2003). However, another method, perhaps faster and less expensive, is to simply present information that leads team members to focus on their similarities. The ability to influence perceived diversity has the potential to go a long way toward leveraging distributed teams for organizational advantage. This, in turn, may increase team effectiveness and decrease turnover as workers become more satisfied with their distributed team experiences. 


\section{References}

Alnuaimi, O. A., L. P. Robert, and L. M. Maruping (2010) "Team Size, Dispersion, and Social Loafing in Technology-Supported Teams: A Perspective on the Theory of Moral Disengagement," Journal of Management Information Systems (27) 1, pp. 203-230.

Amason, A. C. and H. J. Sapienza (1997) "The Effects of Top Management Team Size and Interaction Norms on Cognitive and Affective Conflict," Journal of Management (23) 4, pp. 495-516.

Arazy, O., O. Nov, R. Patterson, and L. Yeo (2011) "Information Quality in Wikipedia: The Effects of Group Composition and Task Conflict," Journal of Management Information Systems (27) 4, pp. 71-98.

Barclay, D. W., C. Higgins, and R. Thompson (1995) "The Partial Least Squares Approach to Causal Modeling: Personal Computer Adoption and Use as Illustration," Technology Studies (2) 2, pp. 285-309.

Barki, H. and J. Hartwick (2004) "Conceptualizing the Construct of Interpersonal Conflict," International Journal of Conflict Management (15) 3, pp. 216-244.

Baron, R. M. and D. A. Kenny (1986) "The Moderator-Mediator Variable Distinction in Social Psychological Research: Conceptual, Strategic, and Statistical Considerations," Journal of Personality and Social Psychology (51) 6, pp. 1173-1182.

Beise, C. M., F. Niederman, and H. Mattord (2004) "IT Project Managers' Perceptions and Use of Virtual Team Technologies," Information Resources Management Journal (17) 4, pp. 73-88.

Bell, S. T. (2007) "Deep-Level Composition Variables as Predictors of Team Performance: A Meta-Analysis," Journal of Applied Psychology (92) 3, pp. 595-615.

Bliese, P. D. (2000) Within-Group Agreement, Non-Independence, and Reliability: Implications for Data Aggregation and Analysis, in K. J. Klein and S. W. J. Kozlowski (Eds.) Multilevel Theory, Research, and Methods in Organizations: Foundations, Extensions, and New Directions, San Francisco, CA: Jossey-Bass, pp. 349-381.

Boh, W. F., Y. Ren, S. Kiesler, and R. Bussjaeger (2007) "Expertise and Collaboration in the Geographically Dispersed Organization," Organization Science (18) 4, pp. 595-612.

Boulding, K. E. (1962) Conflict and Defense: A General Theory. San Francisco, CA: Harper.

Brewer, M. B. (1979) "In-Group Bias in the Minimal Intergroup Situation: A CognitiveMotivational Analysis," Psychological Bulletin (86) 2, pp. 307-24.

Brewer, M. B. (1993) "Social Identity, Distinctiveness, and in-Group Homogeneity," Social Cognition (11) 1, pp. 150-164.

Byrne, D. E. (1971) The Attraction Paradigm. New York, NY: Academic Press.

Cannon-Bowers, J. A., E. Salas, and S. A. Converse (1993) Shared Mental Models in Expert Decision Making Teams, in N. J. Castellan (Ed.) Current Issues in Individual and Group Decision Making, Hillsdale, NJ: Lawrence Erlbaum Associates, pp. 221-246.

Carte, T. and L. Chidambaram (2004) "A Capabilities-Based Theory of Technology Deployment in Diverse Teams: Leapfrogging the Pitfalls of Diversity and Leveraging Its Potential with Collaborative Technology," Journal of the AIS (5) 11-12, pp. 448-471.

Chan, D. (1998) "Functional Relations among Constructs in the Same Content Domain at Different Levels of Analysis: A Typology of Composition Models," Journal of Applied Psychology (83) 2, pp. 234-246.

Chin, W. W. (1998) The Partial Least Squares Approach to Structural Equation Modeling, in G. A. Marcoulides (Ed.) Modern Methods for Business Research, Hillsdale, NJ: Lawrence Erlbaum Associates, pp. 295-336. 
Cialdini, R. B., S. L. Brown, B. P. Lewis, C. Luce et al. (1997) "Reinterpreting the EmpathyAltruism Relationship: When One into One Equals Oneness," Journal of Personality and Social Psychology (73) 3, pp. 481-494.

Cohen, S. G. and D. E. Bailey (1997) "What Makes Teams Work: Group Effectiveness Research from the Shop Floor to the Executive Suite," Journal of Management (23) 3 , pp. 239.

Colquitt, J. A. (2008) "Publishing Laboratory Research in AMJ: A Question of When, Not If," Academy of Management Journal (51) 4, pp. 616-620.

Compeau, D., B. Marcolin, H. Kelley, and C. Higgins (2012) "Generalizability of Information Systems Research Using Student Subjects-a Reflection on Our Practices and Recommendations for Future Research," Information Systems Research (23) 4, pp. 1093-1109.

Cramton, C. D. (2001) "The Mutual Knowledge Problem and Its Consequences for Dispersed Collaboration," Organization Science (12) 3, pp. 346-371.

Cramton, C. D. (2002) "Finding Common Ground in Dispersed Collaboration," Organizational Dynamics (30) 4, pp. 356-367.

Cronin, M. A. and L. R. Weingart (2007) "Representational Gaps, Information Processing, and Conflict in Functionally Diverse Teams," Academy of Management Review (32) 3, pp. 761-773.

Dahlin, K., L. R. Weingart, and P. Hinds (2005) "Team Diversity and Information Use," Academy of Management Journal (46) 6, pp. 1107-1123.

De Dreu, C. K. W. and L. R. Weingart (2003) "Task Versus Relationship Conflict, Team Performance, and Team Member Satisfaction: A Meta-Analysis," Journal of Applied Psychology (88) 4, pp. 741-749.

de Rooija, J., R. Verburga, E. Andriessena, and D. den Hartogb (2007) "Barriers for Shared Understanding in Virtual Teams: A Leader Perspective," The Electronic Journal for Virtual Organizations and Networks (9pp. 1-14.

de Wit, F. R., L. L. Greer, and K. A. Jehn (2012) "The Paradox of Intragroup Conflict: A MetaAnalysis," Journal of Applied Psychology (97) 2, pp. 360-390.

Dennis, A. R., L. P. Robert Jr, A. M. Curtis, S. T. Kowalczyk et al. (2012) "Trust Is in the Eye of the Beholder: A Vignette Study of Postevent Behavioral Controls' Effects on Individual Trust in Virtual Teams," Information Systems Research (23) 2, pp. 546-558.

Deutsch, M., P. T. Coleman, and E. C. Marcus (2006) The Handbook of Conflict Resolution: Theory and Practice. San Fransisco, CA: Jossey-Bass.

Dickey, M. H., M. McLure-Wasko, K. M. Chudoba, and J. Thatcher (2006) "Do You Know What I Know? A Shared Understandings Perspective on Text-Based Communication," Journal of Computer-Mediated Communication (12) 1, pp. 66-87.

Ensley, M. D. and C. L. Pearce (2001) "Shared Cognition in Top Management Teams: Implications for New Venture Performance," Journal of Organizational Behavior (22) 2, pp. 145-160.

Epley, N. and T. Gilovich (2006) "The Anchoring-and-Adjustment Heuristic," Psychological Science (17) 4, pp. 311-318.

Evan, W. M. (1965) "Conflict and Performance in R\&D Organizations: Some Preliminary Findings," Industrial Management Review (7) 1, pp. 37-46.

Ford, M. E. (1992) Motivating Humans: Goals, Emotions, and Personal Agency Beliefs. Newbury Park, CA: Sage Publications, Inc.

Fornell, C. and D. F. Larcker (1981) "Evaluating Structural Equation Models with Unobservable Variables and Measurement Error," Journal of Marketing Research (18) 1, pp. 39-50. 
Garrison, G., R. L. Wakefield, X. Xu, and S. H. Kim (2010) "Globally Distributed Teams: The Effect of Diversity on Trust, Cohesion and Individual Performance," The DATA BASE for Advances in Information Systems (41) 3, pp. 27-48.

Gefen, D. and D. Straub (2005) "A Practical Guide to Factorial Validity Using PLS-Graph: Tutorial and Annotated Example," Communications of the Association for Information Systems (16) 3, pp. 91-109.

Giambatista, R. C. and A. D. Bhappu (2010) "Diversity's Harvest: Interactions of Diversity Sources and Communication Technology on Creative Group Performance," Organizational Behavior and Human Decision Processes (111) 2, pp. 116-126.

Gibson, C. and J. A. Manuel (2003) Building Trust: Effective Multicultural Communication Processes in Virtual Teams, in C. Gibson and S. A. Cohen (Eds.) Virtual Teams That Work: Creating Conditions for Virtual Team Effectiveness, San Francisco, CA: JosseyBass, pp. 59-88.

Goyal, S., L. M. Maruping, and L. P. Robert Jr. (2008) Diversity and Conflict in Teams: A Faultline Model Perspective. Academy of Management Best Paper Proceedings, Anaheim, CA, 2008, pp. 1-6 2008.

Griffith, T. L., M. A. Fuller, and G. B. Northcraft (1998) "Facilitator Influence in Group Support Systems: Intended and Unintended Effects," Information Systems Research (9) 1, pp. 20-36.

Griffith, T. L., E. A. Mannix, and M. A. Neale (2003a) Conflict and Virtual Teams, in C. B. Gibson and S. G. Cohen (Eds.) Virtual Teams That Work, San Francisco, CA: Jossey-Bass, pp. 335-352.

Griffith, T. L., J. E. Sawyer, and M. A. Neale (2003b) "Virtualness and Knowledge in Teams: Managing the Love Triangle of Organizations, Individuals, and Information Technology," MIS Quarterly (27) 2, pp. 265-287.

Hair, J. F., W. C. Black, B. J. Babin, R. E. Anderson et al. (2006) Multivariate Data Analysis. Upper Saddle River, NJ: Pearson-Prentice Hall.

Hair, J. F., C. M. Ringle, and M. Sarstedt (2011) "PLS-SEM: Indeed a Silver Bullet," The Journal of Marketing Theory and Practice (19) 2, pp. 139-152.

Harrison, D. A., K. H. Price, J. H. Gavin, and A. T. Florey (2002) "Time, Teams, and Task Performance: Changing Effects of Surface- and Deep-Level Diversity on Group Functioning," Academy of Management Journal (45) 5, pp. 1029-1045.

Hinds, P. J. and D. E. Bailey (2003) "Out of Sight, out of Sync: Understanding Conflict in Distributed Teams," Organization Science (14) 6, pp. 615-632.

Hinds, P. J. and M. Mortensen (2005) "Understanding Conflict in Geographically Distributed Teams: The Moderating Effects of Shared Identity, Shared Context, and Spontaneous Communication," Organization Science (16) 3, pp. 290-307.

Hinds, P. J. and S. P. Weisband (2003) Knowledge Sharing and Shared Understanding in Virtual Teams, in C. B. Gibson and S. G. Cohen (Eds.) Virtual Teams That Work, San Francisco, CA: Jossey-Bass, pp. 21-36.

Hogg, M. A. and S. C. Hains (1998) "Friendship and Group Identification: A New Look at the Role of Cohesiveness in Groupthink," European Journal of Social Psychology (28) 3, pp. 323-341.

Hsu, J. S., J. Y. Chang, G. Klein, and J. J. Jiang (2011) "Exploring the Impact of Team Mental Models on Information Utilization and Project Performance in System Development," International Journal of Project Management (29) 1, pp. 1-12.

Ilgen, D. R., J. R. Hollenbeck, M. Johnson, and D. Jundt (2005) "Teams in Organizations: From Input-Process-Output Models to IMOI Models," Annual Review of Psychology (56) 1, pp. 517-543. 
James, L. R., R. G. Demaree, and G. Wolf (1984) "Estimating within-Group Interrater Reliability with and without Response Bias," Journal of Applied Psychology (69) 1, pp. 85-98.

Janis, I. L. (1972) Victims of Groupthink: A Psychological Study of Foreign-Policy Decisions and Fiascoes. Oxford, England: Houghton Mifflin.

Janis, I. L. (1982) Groupthink: Psychological Studies of Policy Decisions and Fiascos. Boston, MA: Houghton Mifflin.

Jarvenpaa, S. L., K. Knoll, and D. E. Leidner (1998) "Is Anybody out There?: Antecedents of Trust in Global Virtual Teams," Journal of Management Information Systems (14) 4, pp. 29-64.

Jehn, K., S. Rispens, and S. M. B. Thatcher (2010) "The Effects of Conflict Asymmetry on Workgroup and Individual Outcomes," Academy of Management Journal (53) 3, pp. 596616.

Jehn, K. A. (1995) "A Multimethod Examination of the Benefits and Detriments of Intragroup Conflict," Administrative Science Quarterly (40) 2, pp. 256-282.

Jehn, K. A. (1997) "A Quantitative Analysis of Conflict Types and Dimensions in Organizational Groups," Administrative Science Quarterly (42) 3, pp. 530-557.

Jehn, K. A., C. Chadwick, and S. M. B. Thatcher (1997) "To Agree or Not to Agree: The Effects of Value Congruence, Individual Demographic Dissimilarity, and Conflict on Workgroup Outcomes," International Journal of Conflict Management (8) 4, pp. 287-305.

Jehn, K. A. and J. A. Chatman (2000) "The Influence of Proportional and Perceptual Conflict Composition on Team Performance," International Journal of Conflict Management (11) 1, pp. 56-73.

Jehn, K. A., G. B. Northcraft, and M. A. Neale (1999) "Why Differences Make a Difference: A Field Study of Diversity, Conflict, and Performance in Workgroups," Administrative Science Quarterly (44) 4, pp. 741-763.

Kankanhalli, A., B. C. Y. Tan, and K. K. Wei (2007) "Conflict and Performance in Global Virtual Teams," Journal of Management Information Systems (23) 3, pp. 237-274.

Kirkman, B. L., B. Rosen, C. B. Gibson, P. E. Tesluk et al. (2002) "Five Challenges to Virtual Team Success: Lessons from Sabre, Inc," Academy of Management Executive (16) 3, pp. 67-79.

Klein, K. J. and S. W. Kozlowski (2000) "From Micro to Meso: Critical Steps in Conceptualizing and Conducting Multilevel Research," Organizational Research Methods (3) 3, pp. 211236.

Ko, D. G., L. Kirsch, and W. R. King (2005) "Antecedents of Knowledge Transfer from Consultants to Clients in Enterprise System Implementations," MIS Quarterly (29) 1, pp. 59-85.

Kochan, T., K. Bezrukova, R. Ely, S. Jackson et al. (2003) "The Effects of Diversity on Business Performance: Report of the Diversity Research Network," Human Resource Management (42) 1, pp. 3-21.

Lee, A. S. and R. L. Baskerville (2003) "Generalizing Generalizability in Information Systems Research," Information Systems Research (14) 3, pp. 221-243.

Lipnack, J. and J. Stamps (1997) Reaching across Space, Time, and Organizations with Technology. New York, NY: John, Wiley \& Sons, Inc.

Locke, E. A. and G. P. Latham (1990) "Work Motivation and Satisfaction: Light at the End of the Tunnel," Psychological Science (1) 4, pp. 240-246.

Mannix, E. and M. A. Neale (2005) "What Differences Make a Difference?," Psychological Science in the Public Interest (6) 2, pp. 31-55.

Mannix, E. A., T. L. Griffith, and M. A. Neale (2002) The Phenomenology of Conflict in Virtual Work Teams, in P. Hinds and S. Kiesler (Eds.) Distributed Work, Cambridge, MA: MIT Press, pp. 213-234. 
Marks, M. A., S. J. Zaccaro, and J. E. Mathieu (2000) "Performance Implications of Leader Briefings and Team-Interaction Training for Team Adaptation to Novel Environments," Journal of Applied Psychology (85) 6, pp. 971-986.

Martins, L. L., L. Gilson, L., and M. T. Maynard (2004) "Virtual Teams: What Do We Know and Where Do We Go from Here?," Journal of Management (30) 6, pp. 805-835.

Maruping, L. M. and R. Agarwal (2004) "Managing Team Interpersonal Processes through Technology: A Task-Technology Fit Perspective," Journal of Applied Psychology (89) 6, pp. 975-990.

Mathieu, J. E., T. S. Heffner, G. F. Goodwin, E. Salas et al. (2000) "The Influence of Shared Mental Models on Team Process and Performance," Journal of Applied Psychology (85) 2, pp. 273-283.

Maznevski, M. and K. Chudoba (2001) "Bridging Space over Time: Global Virtual Team Dynamics and Effectiveness," Organization Science (11) 5, pp. 473-492.

McPherson, M., L. Smith-Lovin, and J. M. Cook (2001) "Birds of a Feather: Homophily in Social Networks," Annual Reviews in Sociology (27) 1, pp. 415-444.

Miranda, S. M. and R. P. Bostrom (1993) "The Impact of Group Support Systems on Group Conflict and Conflict Management," Journal of Management Information Systems (10) 3, pp. 63-95.

Montoya-Weiss, M. M., A. P. Massey, and M. Song (2001) "Getting It Together: Temporal Coordination and Conflict Management in Global Virtual Teams," Academy of Management Journal (44) 6, pp. 1251-1262.

Mooney, A. C., P. J. Holahan, and A. C. Amason (2007) "Don't Take It Personally: Exploring Cognitive Conflict as a Mediator of Affective Conflict," Journal of Management Studies (44) 5, pp. 733-758.

Mortensen, M. and P. J. Hinds (2001) "Conflict and Shared Identity in Geographically Distributed Teams," International Journal of Conflict Management (12) 3, pp. 212-238.

Niederman, F. and F. B. Tan (2011) "Managing Global IT Teams: Considering Cultural Dynamics," Communications of the ACM (54) 4, pp. 24-27.

O'Leary, M. and M. Mortensen (2010) "Go (Con) Figure: Subgroups, Imbalance, and Isolates in Geographically Dispersed Teams," Organization Science (21) 1, pp. 115-131.

Ortiz de Guinea, A., J. Webster, and D. S. Staples (2012) "A Meta-Analysis of the Consequences of Virtualness on Team Functioning," Information \& Management (49) 6 , pp. 301-308.

Paul, S., I. M. Samarah, P. Seetharaman, and P. P. Mykytyn Jr (2004) "An Empirical Investigation of Collaborative Conflict Management Style in Group Support SystemBased Global Virtual Teams," Journal of Management Information Systems (21) 3, pp. 185-222.

Pearsall, M. J., A. P. Ellis, and B. S. Bell (2010) "Building the Infrastructure: The Effects of Role Identification Behaviors on Team Cognition Development and Performance," Journal of Applied Psychology (95) 1, pp. 192-200.

Pelled, L. H. (1996) "Demographic Diversity, Conflict, and Work Group Outcomes: An Intervening Process Theory," Organization Science (7) 6, pp. 615-631.

Pelled, L. H., K. M. Eisenhardt, and K. R. Xin (1999) "Exploring the Black Box: An Analysis of Work Group Diversity, Conflict, and Performance," Administrative Science Quarterly (44) 1, pp. 1-28.

Pettigrew, T. F. (1979) "The Ultimate Attribution Error: Extending Allport's Cognitive Analysis of Prejudice," Personality and Social Psychology Bulletin (5) 4, pp. 461-476.

Polzer, J. T., C. B. Crisp, S. L. Jarvenpaa, and J. W. Kim (2006) "Extending the Faultline Model to Geographically Dispersed Teams: How Colocated Subgroups Can Impair Group Functioning," Academy of Management Journal (49) 4, pp. 679-692. 
Powell, A., G. Piccoli, and B. Ives (2004) "Virtual Teams: A Review of Current Literature and Directions for Future Research," The DATA BASE for Advances in Information Systems (35) 1, pp. 6-36.

Preacher, K. J. and A. F. Hayes (2008) "Asymptotic and Resampling Strategies for Assessing and Comparing Indirect Effects in Multiple Mediator Models," Behavior Research Methods (40) 3, pp. 879-891.

Priem, R. L. and K. H. Price (1991) "Process and Outcome Expectations for the Dialectical Inquiry, Devil's Advocacy, and Consensus Techniques of Strategic Decision Making," Group and Organization Studies (16) 2, pp. 206-225.

Rico, R., E. Molleman, M. Sánchez-Manzanares, and G. S. Van der Vegt (2007) "The Effects of Diversity Faultlines and Team Task Autonomy on Decision Quality and Social Integration," Journal of Management (33) 1, pp. 111.

Rispens, S. (2012) "The Influence of Conflict Issue Importance on the Co-Occurrence of Task and Relationship Conflict in Teams," Applied Psychology (61) 3, pp. 349-367.

Robert, L. P., A. R. Dennis, and M. K. Ahuja (2008) "Social Capital and Knowledge Integration in Digitally Enabled Teams," Information Systems Research (19) 3, pp. 314-334.

Robert, L. P., A. R. Dennis, and Y. T. C. Hung (2009) "Individual Swift Trust and KnowledgeBased Trust in Face-to-Face and Virtual Team Members," Journal of Management Information Systems (26) 2, pp. 241-279.

Rogers, E. M. and D. K. Bhowmik (1970) "Homophily-Heterophily: Relational Concepts for Communication Research," Public Opinion Quarterly (34) 4, pp. 523-538.

Rucker, D. D., K. J. Preacher, Z. L. Tormala, and R. E. Petty (2011) "Mediation Analysis in Social Psychology: Current Practices and New Recommendations," Social and Personality Psychology Compass (5) 6, pp. 359-371.

Sarker, S. and J. S. Valacich (2010) "An Alternative to Methodological Individualism: A NonReductionist Approach to Studying Technology Adoption by Groups," MIS Quarterly (34) 4, pp. 779-808.

Staples, D. S. and L. Zhao (2006) "The Effects of Cultural Diversity in Virtual Teams Versus Face-to-Face Teams," Group Decision and Negotiation (15) 4, pp. 389-406.

Straub, D., M.-C. Boudreau, and D. Gefen (2004) "Validation Guidelines for IS Positivist Research," Communications of the Association for Information systems (13) 4, pp. 380427.

Straus, S. G. (1992) Does the Medium Matter? An Investigation of Process, Performance, and Affect in Computer-Mediated and Face-to-Face Groups (Unpublished Dissertation): University of Illinois at Urbana-Champaign.

Straus, S. G. (1999) "Testing a Topology of Tasks: An Empirical Validation of Mcgrath's (1984) Group Task Circumplex," Small Group Research (30) 2, pp. 166-187.

Straus, S. G. and J. E. McGrath (1994) "Does the Medium Matter? The Interaction of Task Type and Technology on Group Performance and Member Reactions," Journal of Applied Psychology (79) 1, pp. 87-97.

Sundstrom, E., K. P. De Meuse, and D. Futrell (1990) "Work Teams: Applications and Effectiveness," American Psychologist (45) 2, pp. 120-133.

Tajfel, H. and J. C. Turner (1979) An Integrative Theory of Intergroup Conflict, in W. G. Austin and S. Worchel (Eds.) The Social Psychology of Intergroup Relations, Monterey, CA: Brooks/Cole Publishing, pp. 33-47.

Tajfel, H. T. and J. C. Turner (1986) The Social Identity Theory of Intergroup Behavior, in S. Worchel and L. W. Austin (Eds.) Psychology of Intergroup Relations, Chicago, IL: Nelson-Hall, pp. 2-24. 
Turner, J. C. (1985) Social Categorization and the Self-Concept: A Social Cognitive Theory of Group Behavior, in E. J. Lawler (Ed.) Advances in Group Processes: Theory and Research, Greenwich, CT: JAI Press, pp. 77-122.

Tversky, A. and D. Kahneman (1974) "Judgment under Uncertainty: Heuristics and Biases," Science (185) 4157, pp. 1124-1131.

Vignovic, J. A. and L. F. Thompson (2010) "Computer-Mediated Cross-Cultural Collaboration: Attributing Communication Errors to the Person Versus the Situation," Journal of Applied Psychology (95) 2, pp. 265-276.

Zellmer-Bruhn, M. E., M. M. Maloney, A. D. Bhappu, and R. Salvador (2008) "When and How Do Differences Matter? An Exploration of Perceived Similarity in Teams," Organizational Behavior and Human Decision Processes (107) 1, pp. 41-59.

Zhao, X., J. G. Lynch, and Q. Chen (2010) "Reconsidering Baron and Kenny: Myths and Truths About Mediation Analysis," Journal of Consumer Research (37) 2, pp. 197-206. 


\section{Appendix A: Instructions and Case Overview}

\section{TASK INSTRUCTIONS}

In the following exercise, your group will be asked to make a recommendation of action regarding a situation in which a college student bribed an instructor to change his grade in a course. The following pages describe the circumstances and the possible courses of action. Your task is to work as a group and determine which courses of disciplinary action to choose for the student and the instructor. Your group should consider the consequences of the different actions when making its decision.

There are several departments on campus that have preferences for how this matter should be settled. The solution that your group comes up with will be scored in terms of how satisfying it is to the different departments.

The more your solution maximizes the interests of all parties, the better your group will do.

Please take a few minutes to read the case on the following pages.

\section{DISCIPLINARY ACTION CASE}

This case involves determining the disciplinary actions for a situation in which a college student athlete has been found guilty of bribing an instructor to change his grade in a course. This event took place at a prestigious liberal arts college in the eastern U.S. The student, Jack, is a star athlete on the college basketball team. He leads the team in points, assists, blocked shots, and rebounds. He is very popular and has drawn larger crowds at the game than in previous seasons, substantially increasing the college's revenues due to athletics. In fact, Jack is such a good player and is so popular that the school has received a great deal of positive attention from the press, enhancing the college's reputation and attracting student enrollment.

Jack had been concerned about a grade in one of his courses. He needed a B or better on the midterm exam to get a $B$ in the course and remain eligible to play basketball. He received a $D$ on the midterm. To maintain his eligibility, he offered $\$ 500$ to the course's graduate student instructor to change his exam grade to a B. The instructor, Tom, accepted the offer. Another instructor learned of the incident and reported both Jack and Tom to the administration. When confronted, Jack and Tom admitted to what they had done.

As the disciplinary action committee, your group's task is to choose the best courses of disciplinary action. There are five issues to settle in the case. 
Three issues pertain to disciplining Jack; including what to do about:

1. Jack's grade in the course

2. Jack's status on the basketball team

3. Jack's status as a college student

The other two issues pertain to disciplining Tom; including what to do about:

4. Tom's status as an instructor

5. Tom's status as a graduate student

When considering the alternatives for each issue, you should consider the consequences of the various options. In addition, be sure that you do not choose an illogical combination of alternatives (e.g., if you decide to suspend Jack from the academic program for one semester, then he cannot be suspended from playing basketball for only one game; if you decide to expel Tom from school, then he cannot work for the college as a teacher). The following information describes the different departments' preferences and the possible courses of disciplinary action for each of the five matters.

The athletic department does not condone cheating, however, it does not want to lose Jack from the team due to a suspension or expulsion. With Jack on the team, the school has a good chance at winning the conference championship. Without Jack, the college is unlikely to win the championship. In addition, the money brought in from attendance at the games due to Jack's popularity has increased this department's resources, which it does not want to lose. On the grounds that extreme punishment for either Jack or Tom would only hurt the school and serve no useful purpose, the athletic department supports a lenient course of disciplinary action.

The college faculty wishes to uphold the highest academic and ethical principles. After all, the main purpose of the college is as an academic institution. The faculty believes that cheating is reprehensible; is it the academic equivalent of theft and fraud, and the harshest punishment should be given to both Jack and Tom. In addition, a harsh and publicized disciplinary action will send a message to others that cheating is not tolerated at this college. This message will have a positive effect on the college's reputation for high academic standards. If the punishment is too light, then a precedent of lenience will be set for cases in the future, conveying the message that cheating is condoned, or it will convey a message of inequality - that different standards apply to different students.

The college's administration wants a solution that takes into account the preferences of both the athletic department and faculty positions and protects the college's public image. The administration wants to ensure the continued success of the athletic program. It also 
wants to uphold the college's academic standards and principles. Both the athletic and academic programs have contributed to the college's positive reputation. The administration is concerned that this matter be handled very carefully or the college may jeopardize its reputation, future enrollment, and financial support from other institutions and alumni.

As a committee, your task is to agree on how to settle this matter. Your group must agree on one option to resolve each of the five issues. Remember, the more your solution takes into account the concerns of all parties, the better your group will do. If you cannot come to an agreement on an issue, skip it and come back later. When you come to agreement on an issue, all group members should record the group's decisions and the rationale for each decision on the form entitled "Group Decisions". Please write legibly.

You are limited to the courses of action presented on the next page. Assume you have all necessary information and that all information given is accurate.

After you've read the issues and possible courses of actions on the next page, stop and wait for a researcher to tell you to begin working on the task. 


\section{Table 1A. Issues and Possible Solutions for Case}

Issue 1: Jack's grade in the course

1a. Give Jack his original grade on the exam (a D).

1b. Give Jack a failing grade on the exam.

1c. Give Jack a failing grade in the course.

Issue 2: Jack's status on the basketball team

2a. Make no change in Jack's basketball eligibility.

$2 b$. Suspend Jack from the next basketball game.

2c. Suspend Jack from the basketball team for the rest of the season.

$2 \mathrm{~d}$. Suspend Jack from the basketball team for an indefinite length of time; require that he appeal to be reinstated.

2e. Kick Jack off the team.

Issue 3: Jack's status as a college student

3a. Make no change in Jack's college status.

3b. Give Jack a warning, stating that if he is involved in another incident involving cheating in the future, he will be expelled.

3c. Suspend Jack from college (classes and athletics) for the rest of the semester.

3d. Suspend Jack from the college for an indefinite length of time; require appeal for re-admittance.

3e. Expel Jack from the college.

Issue 4: Tom's status as an instructor (note: If Tom is restricted from teaching, he loses a source of income that helps pay his way through grad school. He will also have trouble getting a job without teaching experience.)

4a. Make no change in Tom's teaching status.

4b. Give Tom a reprimand to be placed in his permanent record, which will be seen by potential employers after he is finished with school.

4c. Suspend Tom from teaching for the rest of the semester

$4 \mathrm{~d}$. Suspend Tom from teaching for an indefinite length of time; require that he appeal to be reinstated.

4e. Do not allow Tom to teach again during his time remaining in graduate school.

Issue 5: Tom's status as a graduate student

5a. Make no change in Tom's college status

5b. Give Tom a warning - if he is involved in another incident involving cheating in the future, he'll be expelled.

5c. Suspend Tom from the college for the rest of the semester.

$5 \mathrm{~d}$. Suspend Tom from the college for an indefinite length of time; require that he appeal for readmittance.

5e. Expel Tom from the college. 


\section{Appendix B: E-Profile Content}

\section{Section 1: Demographics}

1. Age:

2. Gender:

3. My marital status is:

4. My ethnicity is:

5. My sexual orientation is:

6. The continent I am from is:

7. (If from the United States) The region I am from is the:

8. I grew up primarily in the:

9. My family's socio-economic status is:

10. Which best describes your employment status?

11. My parent's highest educational level is:

12. Do you live with your parents?

13. If you don't live with your parents, do you live on campus?

14. If you don't live with your parent(s), do you have a roommate or partner living with you?

15. Do you have children?

16. Do you want children someday?

17. Do you have pets?

18. Do you want to have pets someday?

19. Do you have siblings?

20. My zodiac sign is:

21. What type of student are you?

22. What year are you in your studies?

23. Do you plan to attend graduate school?

24. Do you plan to attend graduate school at this university?

Section 2: Values, Attitudes, Beliefs

25. My political orientation is closest to:

26. My religious orientation is closest to:

27. Rate the degree to which you are involved in religious activities:

28. Ethical behavior is:

29. If a situation involves NO threat to a person's physical well-being, to what extent is it ok to "break the rules"?

30. How harshly should non-violent offenders be punished (e.g., people who commit fraud, forgery, accept bribes, cheat on their taxes...)?

31. The best outcome is one which benefits:

32. I believe in:

33. The following social issues are very important to me:

34. The areas of my life that are MOST important to me are:

35. My attitude towards learning is:

36. Education is:

37. How important to you is the reputation of [REDACTED] university?

\section{Section 3: Personality/Cognition/Emotion}

Which trait do you identify with more?

38. reserved OR warm

39. concrete reasoning OR abstract reasoning

40. reactive OR emotionally stable 


\begin{tabular}{|l|}
\hline 41. submissive OR dominant \\
\hline 42. serious OR lively \\
\hline 43. believe "the ends justify the means" OR rule-conscious \\
\hline 44. shy OR socially bold \\
\hline 45. stoic, unemotional OR sensitive \\
\hline 46. trusting OR vigilant \\
\hline 47. practical OR imaginative \\
\hline 48. forthright OR private \\
\hline 49. self-assured OR apprehensive \\
\hline 50. traditional OR open-to-change \\
\hline 51. group-oriented OR self-reliant \\
\hline 52. tolerates disorder OR perfectionist \\
\hline 53. relaxed OR tense \\
\hline 54. leader OR follower \\
\hline 55. I am usually: \\
\hline 56. Are you generally happy with your life now? \\
\hline 57. My style of addressing conflict is: \\
\hline 58. I would describe my sense of humor as: \\
\hline 59. In terms of work ethic: \\
\hline Section 4: Knowledge, Skills, Abilities \\
\hline 60. I excel in the following subject areas: \\
\hline 61. How hard do you work for the grades you earn? \\
\hline 62 . My major area of study is: \\
\hline 63. I prefer the following types of tasks: \\
\hline 64. I excel at the following types of tasks: \\
\hline Section 5: Personal Interests and Preferences \\
\hline 65. What hobbies or interests do you have? \\
\hline 66. What types of music do you enjoy listening to? \\
\hline 67. Are you a student athlete? \\
\hline 68. My favorite athletic events include: \\
\hline 69. How much of a sports' fan are you? \\
\hline 70. My favorite types of movies and/or books include: \\
\hline 71. Do you participate in a Greek organization? \\
\hline 72. My favorite color is: \\
\hline 73. My favorite cuisines/foods are: \\
\hline 74. In terms of pets, I prefer... \\
\hline 75. My favorite types of television shows include: \\
\hline
\end{tabular}

Notes: Items 1, 2, 4, and 6 were collected as potential control variables. They were not displayed to participants. 


\section{Appendix C: Team Effectiveness Scoring Procedure}

To illustrate the team effectiveness scoring procedure, consider a team that makes the following selections as their solutions to the task:

1a. Give Jack a failing grade on the exam.

2c. Suspend Jack from the basketball team for the rest of the season.

3b. Give Jack a warning that if he is involved in another incident, he will be expelled.

4c. Suspend Tom from teaching for the rest of the semester.

5c. Suspend Tom from the college for the rest of the semester.

The calculations used to determine the team effectiveness score are illustrated in Table 1B, the weights and point values involved in the calculations are shown in Table 2B (Straus, 1992; Straus and McGrath, 1994). Using Table 2B, each set of points for an option are multiplied by their respective weights. The points reflect the degree to which that solution supports a given constituency's interests, while the weights reflect its importance for a given constituency. The product of these two values (representing interest maximization and importance of the issue) produces a constituency's score for that issue (e.g., 1*1 for Faculty, 3*1 for Athletic Department, 2*1 for Administration on Issue 1, option a). The scores are summed within constituencies (e.g., 13 for Faculty, 16 for Athletic Department, 22 for Administration), and multiplied across constituencies to produce a final team effectives score (e.g., 4576).

\section{Table 1B. Team Effectiveness Scoring Example}

\begin{tabular}{|c|c|c|c|c|c|c|}
\hline \multirow{2}{*}{$\begin{array}{l}\text { Issue \& } \\
\text { Choice }\end{array}$} & \multicolumn{2}{|c|}{ Faculty } & \multicolumn{2}{|c|}{ Athletic Department } & \multicolumn{2}{|c|}{ Administration } \\
\hline & Score & Weight & Score & Weight & Score & Weight \\
\hline $1 a$ & 1 & 1 & 3 & 1 & 2 & 1 \\
\hline $2 c$ & 0 & -- & 1 & 4 & 1 & 4 \\
\hline $3 b$ & 1 & 2 & 3 & 3 & 3 & 2 \\
\hline $4 c$ & 2 & 3 & 0 & -- & 2 & 3 \\
\hline \multirow[t]{2}{*}{$5 c$} & 2 & 2 & 0 & -- & 2 & 2 \\
\hline & \multicolumn{2}{|c|}{$\begin{array}{c}=\left(1^{*} 1\right)+(0)+(1 * 2)+ \\
(2 * 3)+(2 * 2) \\
=13\end{array}$} & \multicolumn{2}{|c|}{$\begin{array}{c}=\left(3^{*} 1\right)+(1 * 4)+\left(3^{*} 3\right)+ \\
(0)+(0) \\
=16\end{array}$} & \multicolumn{2}{|c|}{$\begin{array}{c}=\left(2^{*} 1\right)+(1 * 4)+\left(3^{*} 2\right)+ \\
\left(2^{*} 3\right)+\left(2^{*} 2\right) \\
=22\end{array}$} \\
\hline Final Score & & & $13 * 1$ & 4576 & & \\
\hline
\end{tabular}




\begin{tabular}{|c|c|c|c|c|}
\hline & \multirow[b]{2}{*}{ Issue \& Choice } & \multicolumn{3}{|c|}{ Constituencies } \\
\hline & & Faculty & $\begin{array}{c}\text { Athletic } \\
\text { Department }\end{array}$ & Administration \\
\hline \multirow{4}{*}{ 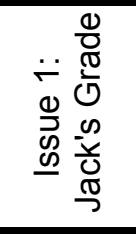 } & Weight & 1 & 1 & 1 \\
\hline & $1 \mathrm{a}$ & 1 & 3 & 2 \\
\hline & $1 \mathrm{~b}$ & 2 & 2 & 3 \\
\hline & $1 \mathrm{c}$ & 3 & 0 & 1 \\
\hline \multirow{6}{*}{ 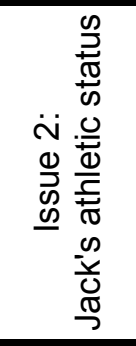 } & Weight & -- & 4 & 4 \\
\hline & $2 a$ & 0 & 4 & 4 \\
\hline & $2 b$ & 0 & 3 & 3 \\
\hline & $2 \mathrm{c}$ & 0 & 2 & 2 \\
\hline & $2 d$ & 0 & 1 & 1 \\
\hline & $2 e$ & 0 & 0 & 0 \\
\hline \multirow{6}{*}{ 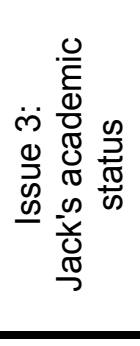 } & Weight & 2 & 3 & $\underline{2}$ \\
\hline & $3 a$ & 0 & 4 & 1 \\
\hline & $3 b$ & 1 & 3 & 3 \\
\hline & $3 c$ & 2 & 2 & 2 \\
\hline & $3 d$ & 3 & 1 & 2 \\
\hline & $3 e$ & 4 & 0 & 0 \\
\hline \multirow{6}{*}{ 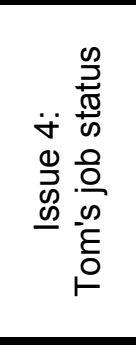 } & Weight & 3 & -- & 3 \\
\hline & $4 a$ & 0 & 0 & 0 \\
\hline & $4 b$ & 1 & 0 & 1 \\
\hline & $4 \mathrm{c}$ & 2 & 0 & 2 \\
\hline & $4 d$ & 3 & 0 & 3 \\
\hline & $4 e$ & 4 & 0 & 4 \\
\hline \multirow{6}{*}{ 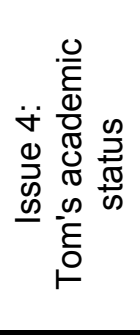 } & Weight & 2 & - & $\underline{2}$ \\
\hline & $5 a$ & 0 & 0 & 0 \\
\hline & $5 b$ & 1 & 0 & 1 \\
\hline & $5 c$ & 2 & 0 & 2 \\
\hline & $5 d$ & 3 & 0 & 3 \\
\hline & $5 e$ & 4 & 0 & 4 \\
\hline
\end{tabular}




\section{Appendix D: Alternative Mediation Analysis}

Baron and Kenny's (1986) method has been used for decades to test mediated relationships in the social sciences. Despite recent criticism of causal step approaches (Preacher and Hayes, 2008; Rucker et al., 2011; Zhao et al., 2010), Baron and Kenny's method remains powerful in its simplicity and familiarity. Thus, we felt it useful to report the results of mediation testing using this method in addition to the results reported using Preacher and Hayes' technique (2008).

Baron and Kenny's (1986) approach stipulates that for mediation to be demonstrated, three conditions must be met: (1) the independent variables must significantly impact the dependent variable; (2) the mediator must significantly impact the dependent variable; and (3) the impact of the independent variable on the dependent variable must either weaken (i.e., in the case of partial mediation) or become non-significant (i.e., in the case of full mediation) in the presence of the mediator.

Table $1 \mathrm{C}$ shows the results of this analysis. Results show that e-profile use does not significantly impact relational conflict (Model 3), failing to meet condition 2 described above. However, e-profile use is significantly related to both task conflict and shared understanding (Models 4 and 1 , respectively), meeting conditions 1 and 2 above. Moreover, in the presence of task conflict, eprofile use is significant and the strength of this relationship diminishes (from .62 to .41), supporting partial mediation. These results are consistent with our findings using the Preacher and Hayes (2008) approach. We also assessed whether the impact of relational conflict and task conflict, respectively, on team effectiveness would be mediated through shared understanding. Table $1 \mathrm{C}$ shows that both types of conflict are significantly related to team effectiveness (Model 5), however, only task conflict significantly impacts shared understanding (Model 8). Condition 2 described above is not met in the case of relational conflict (Model 7). Model 6 in Table 1C shows that the influence of task conflict on team effectiveness becomes non-significant in the presence of shared 
understanding, supporting full mediation. These results are again consistent with our findings using the Preacher and Hayes (2008) approach.

\section{Table 1C. Mediation Analysis using Baron and Kenny Approach}

\begin{tabular}{|c|c|c|c|c|c|c|c|c|}
\hline \multirow[b]{2}{*}{ Mediators } & \multicolumn{2}{|c|}{$\begin{array}{l}\text { Model } 1 \text { DV: Shared } \\
\text { Understanding }\end{array}$} & \multicolumn{2}{|c|}{$\begin{array}{c}\text { Model } 2 \text { DV: Shared } \\
\text { Understanding }\end{array}$} & \multicolumn{2}{|c|}{$\begin{array}{c}\text { Model } 3 \text { DV: } \\
\text { Relational Conflict }\end{array}$} & \multicolumn{2}{|c|}{$\begin{array}{l}\text { Model } 4 \text { DV: } \\
\text { Task Conflict }\end{array}$} \\
\hline & $\beta$ & SE & $\beta$ & SE & B & SE & $\beta$ & SE \\
\hline e-profile use & $.62^{* * *}$ & .22 & $.41^{* *}$ & .28 & -.15 & .27 & $-.64^{* * *}$ & .15 \\
\hline $\begin{array}{l}\text { Relational } \\
\text { Conflict }\end{array}$ & & & -.05 & .12 & & & & \\
\hline \multirow[t]{2}{*}{ Task Conflict } & & & $-.30^{*}$ & .21 & & & & \\
\hline & \multicolumn{2}{|c|}{$\begin{array}{l}\text { Model } 5 \text { DV: Team } \\
\text { Effectiveness }\end{array}$} & \multicolumn{2}{|c|}{$\begin{array}{l}\text { Model } 6 \text { DV: Team } \\
\text { Effectiveness }\end{array}$} & \multicolumn{2}{|c|}{$\begin{array}{l}\text { Model } 7 \text { DV: Shared } \\
\text { Understanding }\end{array}$} & \multicolumn{2}{|c|}{$\begin{array}{l}\text { Model } 8 \text { DV: Shared } \\
\text { Understanding }\end{array}$} \\
\hline $\begin{array}{l}\text { Relational } \\
\text { Conflict }\end{array}$ & $-.43^{\star * *}$ & 388.51 & $-.38^{* * *}$ & 325.74 & -.12 & .15 & & \\
\hline Task Conflict & $-.41^{* *}$ & 527.22 & -.10 & 530.70 & & & $-.56^{\star * *}$ & .17 \\
\hline $\begin{array}{l}\text { Shared } \\
\text { Understanding }\end{array}$ & & & $.55^{\star * *}$ & 384.54 & & & & \\
\hline
\end{tabular}

Note: $\mathrm{N}=46 ;{ }^{*} \mathrm{p}<.05,{ }^{* *} \mathrm{p}<.01,{ }^{* * *} \mathrm{p}<.001$. 